\title{
Uplift soil resistance to a shallowly-buried pipeline in the sandy seabed under waves: Poro-elastoplastic modeling
}

\author{
Wen-Gang Qi ${ }^{\mathrm{a}, \mathrm{b}}$, Yu-Min Shi ${ }^{\mathrm{a}, \mathrm{b}}$, Fu-Ping Gao ${ }^{\mathrm{a}, \mathrm{b}, *}$ \\ ${ }^{a}$ Key Laboratory for Mechanics in Fluid Solid Coupling Systems, Institute of Mechanics, Chinese Academy of Sciences, Beijing 100190, China \\ ${ }^{\mathrm{b}}$ School of Engineering Science, University of Chinese Academy of Sciences, Beijing 100049, China
}

\section{A R T I C L E I N F O}

\section{Keywords:}

Wave-seabed-pipeline interaction

Poro-elastoplastic model

Buried pipe

Transient pore-pressure response

Vertical soil resistance

\begin{abstract}
A B S T R A C T
A reasonable evaluation of the vertical soil resistance to a buried pipeline is crucial for upheaval buckling analyses. Under wave troughs, the effective stress in the seabed could be reduced significantly due to the upward seepage caused by vertical pore-pressure gradients. To investigate the influence of wave loading on the vertical soil resistance to a buried pipe, a plane-strain poro-elastoplastic model is proposed and verified with the existing pipe-soil interaction test results and DNV GL predictions. The model is capable of sequentially simulating the pore-pressure generation in a sandy seabed under waves and the plastic-zone development while uplifting the pipe. Numerical results show that the presence of wave troughs could not only reduce the soil effective stress, but also generate an additional uplift force on the buried pipe due to non-uniform distribution of pore-pressures along the pipe periphery. The normalized additional uplift force generally increases linearly with normalized amplitude of wave pressures at seabed mudline. Parametric study is then performed to examine the influence of wave parameters and soil properties. Moreover, to qualitatively characterize the effect of wave loading, a resistance-reduction coefficient is introduced and found to decrease linearly with the increase of normalized amplitude of wave pressure at seabed mudline.
\end{abstract}

\section{Introduction}

The upheaval global buckling of buried submarine pipelines could occur due to the axial compressive forces induced by thermal and internal pressure actions during operational cycles of heating and cooling of the pipeline [9]. While a buried pipe is inclined to move upward, the vertical soil resistance to the pipe can be mobilized correspondingly. As such, a proper evaluation of the vertical soil resistance is a key concern for assessing the global buckling of buried pipelines [36,37].

In the past a few decades, several formulas were ever proposed to evaluate the vertical soil resistance to a buried pipe subjected to lift forces. Among them, the vertical slip model was one of the widely adopted methods [24], which described the peak vertical soil resistance to a shallowly-embedded pipe by the sum of the submerged weight of the lifted internal prism above the pipe and the vertical shear force along the two vertical planes of the internal prism. Trautmann et al. [32] later conducted a series of experiments to investigate the effects of soil density and burial-depth on the response of an uplifted pipe. Recently, White et al. [35] reviewed previous models for the peak vertical soil resistance. They classified the models into two categories, i.e. limit equilibrium models and plasticity ones, and further proposed a limit equilibrium solution for predicting the peak vertical soil resistance of buried pipes and plate anchors in sands. Cheuk et al. [4] also summarized different mechanisms and their corresponding prediction formulas for the peak vertical soil resistance. It was recognized that the aforementioned vertical slip model is convenient to employ but may overestimate the peak values of vertical soil resistance. Byrne et al. [1] measured both the vertically upward force exerting onto a pipe and the excess pore-pressure around the pipe at different loading rates in the saturated very loose sand. Their results indicated that the uplift resistance could be decreased due to the positive excess pore-pressure generated in the proximity of the pipe. The vertical slip model was then modified to reflect the effect of excess pore-pressure under partially drained loading conditions.

It should be noted that the flow-structure-soil interaction is one of the essential features for the response of subsea structures (see [19]), e.g. the instability of submarine pipelines $[12,14]$. During storm events in shallow or transitional waters, the gravitational waves would impose hydrodynamic loads onto the seabed (see the analytical solutions by Yamamoto et al. [38]), Madsen [22], Hsu and Jeng [17]; and the recent

\footnotetext{
* Corresponding author at: Key Laboratory for Mechanics in Fluid Solid Coupling Systems, Institute of Mechanics, Chinese Academy of Sciences, No. 15 Beisihuanxi Road, Beijing 100190, China.

E-mail address: fpgao@imech.ac.cn (F.-P. Gao).
} 


\begin{tabular}{|c|c|c|c|}
\hline \multirow{2}{*}{\multicolumn{2}{|c|}{ Notation }} & $L$ & Wave length \\
\hline & & $n$ & Porosity of the soil \\
\hline \multirow{2}{*}{\multicolumn{2}{|c|}{ The following symbols are used in this paper }} & $P_{0}$ & Amplitude of wave pressure at the mudline \\
\hline & & $p^{\prime}$ & Mean effective stress \\
\hline$b_{\mathrm{i}}$ & Body acceleration per unit mass & $p$ & Wave-induced pore-pressure in the soil \\
\hline$c$ & Cohesion strength & $p_{0}$ & Wave pressure at the mudline \\
\hline$D$ & Diameter of pipeline & $t$ & Time \\
\hline \multirow[t]{2}{*}{$D_{\mathrm{ijkl}}^{\mathrm{e}}$} & Elements of constitutive matrix to describe the con- & $T$ & Wave period \\
\hline & stitutive stress-strain relation & $u^{s}$ & Soil displacement \\
\hline$d$ & Burial-depth of pipeline (measured to the top of pipeline) & $W_{\mathrm{p}}^{\prime}$ & Submerged weight of the pipeline per unit length \\
\hline$d_{0}$ & Seabed thickness & $x^{\mathrm{s}}$ & Direction of wave propagation \\
\hline$E_{\mathrm{p}}$ & Young's modulus of pipeline & $z$ & Soil depth relative to the mudline \\
\hline$E_{\mathrm{s}}$ & Elastic modulus of soil & $\delta_{\mathrm{ij}}$ & Kronecker delta \\
\hline$f$ & Vertical soil resistance factor & $\varepsilon_{\mathrm{ij}}$ & Strain tensor \\
\hline$F_{\mathrm{b}}$ & $\begin{array}{l}\text { Vertical uplift force associated with thermal and internal } \\
\text { pressure }\end{array}$ & $\begin{array}{l}\varepsilon_{\mathrm{ii}} \\
\phi\end{array}$ & $\begin{array}{l}\text { Volumetric strain of soil } \\
\text { Peak friction angle of soil }\end{array}$ \\
\hline$F_{\mathrm{r}}$ & $\begin{array}{l}\text { Vertical soil resistance under wave troughs acting on the } \\
\text { pipeline per unit length }\end{array}$ & $\begin{array}{l}\phi_{\mu} \\
\gamma^{\prime}\end{array}$ & $\begin{array}{l}\text { Friction angle of the pipe-soil interface } \\
\text { Submerged unit weight of soil }\end{array}$ \\
\hline$F_{\mathrm{rp}}$ & $\begin{array}{l}\text { Peak vertical soil resistance under wave troughs acting on } \\
\text { the pipeline per unit length }\end{array}$ & $\begin{array}{l}\gamma_{d} \\
\gamma_{w}\end{array}$ & $\begin{array}{l}\text { Dry unit weight of soil } \\
\text { Unit weight of water }\end{array}$ \\
\hline$F_{\mathrm{rp} 0}$ & $\begin{array}{l}\text { Peak vertical soil resistance without waves acting on the } \\
\text { pipeline per unit length }\end{array}$ & $\lambda$ & $\begin{array}{l}\text { Lame's constant } \\
\text { Friction coefficient of pipe-soil interface }\end{array}$ \\
\hline$F_{\mathrm{w}}$ & $\begin{array}{l}\text { Wave-induced additional uplift force acting on pipeline } \\
\text { under wave troughs }\end{array}$ & $\begin{array}{l}\nu_{\mathrm{p}} \\
\nu_{\mathrm{s}}\end{array}$ & $\begin{array}{l}\text { Poisson ratio of pipeline } \\
\text { Poisson ratio of soil }\end{array}$ \\
\hline G & Shear modulus of soil & $\theta$ & Lode's angle \\
\hline$g$ & Gravitational acceleration & $\rho$ & Density of soil \\
\hline$H_{\mathrm{c}}$ & Burial-depth to the center of pipeline & $\rho_{\mathrm{f}}$ & Density of pore water \\
\hline$H$ & Wave height & $\rho_{\mathrm{s}}$ & Density of soil grains \\
\hline$h$ & Water depth & $\sigma_{\mathrm{ij}}$ & Total stress tensor \\
\hline$J$ & Deviatoric stress invariant & $\sigma_{i j}^{\prime}$ & Effective stress tensor \\
\hline$K_{0}$ & Coefficient of earth pressure at rest & $\tau$ & Frictional shear stress at pipe-soil interface \\
\hline$K^{\prime}$ & Apparent bulk modulus of pore water & $\tau_{\text {crit }}$ & Critical frictional shear stress at pipe-soil interface \\
\hline$k$ & Wave number, $k=2 \pi / L$ & $\omega$ & Angular frequency of the wave \\
\hline$k_{\mathrm{s}}$ & Darcy's permeability coefficient & $\psi$ & Dilation angle of soil \\
\hline
\end{tabular}

wave flume observations by Qi et al. [27]). Under wave troughs, the negative transient pore-pressure can be generated in the sandy seabed, which could further have a considerable influence on the buried pipe in the following two aspects. On the one hand, the non-uniform distribution of pore-pressures along the pipe periphery can result in an additional uplift force onto the pipe. Meanwhile, the confining pressure in the upper soil layer above the pipe could be significantly reduced due to the upward seepage force (see [26]). Both the presence of additional uplift force and the reduction of confining pressure under wave troughs would consequently threaten the stability of shallowly-buried pipelines. With regard to the wave-induced pore-pressure around and the additional uplift force on the buried pipe, quite a few investigations have been intensively performed under the framework of porous media theory, e.g. the analytical solutions by Spierenburg [29] and MacDougal et al. [21], the experimental and numerical simulations by Magda [23], Gao et al. [13], Gao and Wu [15], Zhou et al. [41], Duan et al. [11], and Chen et al. [3]. Although those investigations were mainly focused on the pore-pressure response around a "fixed" buried pipe, their advances motivated the authors to further reveal the mechanism of vertical pipe-soil interactions for a lifted pipe in the sandy seabed under waves.

In the present study, a plane-strain poro-elastoplastic model is proposed for sequentially simulating the pore-pressure generation in a sandy seabed under waves and the plastic-zone development while uplifting a shallowly-buried pipe. The numerical model is then verified with the existing pipe-soil interaction test results and DNV GL predictions. Moreover, a parametric study is conducted to examine the effects of wave and soil parameters on the vertical soil resistance to a shallowly-buried pipe.
2. Poro-elastoplastic model for vertical pipe-soil interaction under waves

\subsection{Geometric model and finite element mesh}

The pipe-soil interaction under ocean waves travelling perpendicularly to a buried pipe can be regarded as a plane strain problem. A plane-strain poro-elastoplastic model is developed to simulate the uplifting pipe-soil interaction taking into account of wave loading effects. Both the wave-induced pore-pressure and the corresponding elastoplastic strain of the soil around the uplifting buried pipe can be simulated sequentially.

As shown in Fig. 1, a submarine pipeline (with outer diameter of $D$ ) is shallowly-buried in a sandy seabed. The z-direction is downward from the mudline and the waves propagate in the positive $x$-direction. The pipe may experience a net upward force and upheaval buckling would be initiated if the sum of the vertical soil resistance $\left(F_{\mathrm{r}}\right)$ and the submerged weight of the pipe $\left(W_{\mathrm{p}}^{\prime}\right)$ is exceeded by the sum of the vertical uplift force associated with thermal and internal pressure $\left(F_{\mathrm{b}}\right)$ and the wave-induced additional uplift force on the pipe $\left(F_{\mathrm{w}}\right)$ (i.e. $F_{\mathrm{r}}+W_{\mathrm{p}}^{\prime} \geq F_{\mathrm{b}}+F_{\mathrm{w}}$ )

Fig. 2 illustrates the meshes of a buried pipe and its surrounding soil. The width of the whole numerical model is set as $250 \mathrm{~m}$ (over three times of the wavelength) and the depth as $20 \mathrm{~m}$. Such size of soil domain was found to be sufficient for diminishing boundary effects. The pipe is located under the wave trough and at $0.5 \mathrm{~m}$ depth from the pipe top. The pipe is simulated with 4-node bilinear plane strain reducedintegration elements (CPE4R); and the soil is simulated with the CPE4RP element (4-node plane strain, bilinear displacement, bilinear 


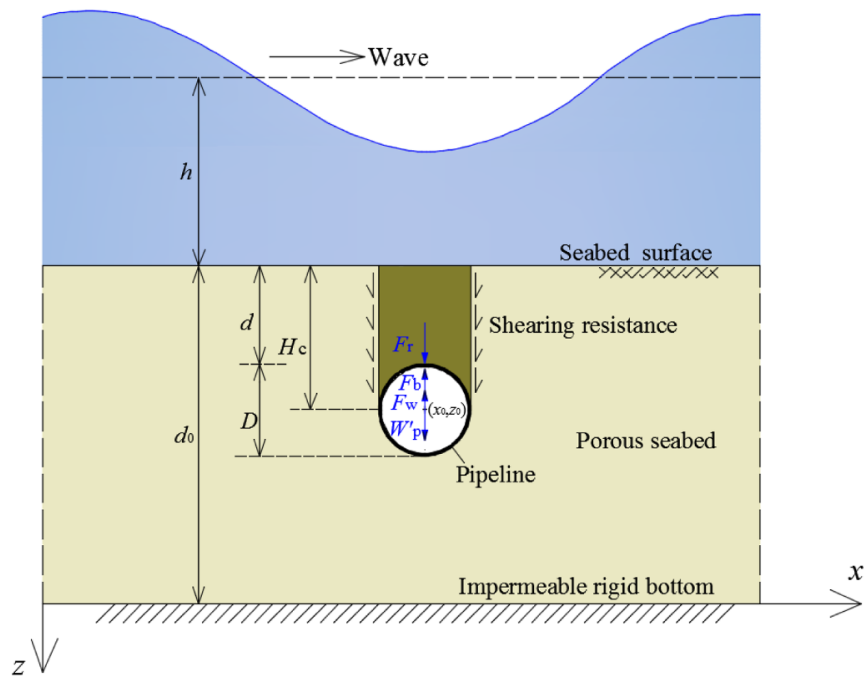

Fig. 1. Illustration of vertical pipe-soil interaction for an uplifted buried pipe under the wave trough.

pore-pressure, reduced-integration). In this numerical simulations, we focus on the development of pore-pressure and plastic failure of the soil in the vicinity of the buried pipe. Therefore, the computational grids get denser in the closer proximity to the pipe (see Fig. 2). The grid size of the present model has been proved fine enough for the computational accuracy by comparing results between the models with various grid sizes.

\subsection{Major assumptions and governing equations}

Major assumptions for modeling the vertical pipe-soil interaction and wave-induced transient pore-pressure around the pipe buried in the porous seabed are described as follows.

(1) The sandy seabed is assumed to be homogeneous and isotropic. Both the porosity and the elastoplasticity of the sandy seabed are taken into account in the proposed poro-elastoplastic model.

(2) The vertically lifted pipe-soil interaction under waves is regarded as a quasi-static process. The analyses of Ulker et al. [33] indicated that the difference between the fully dynamic solution and that for the quasi-static appears to be less than $5 \%$ at most. That is, the inertia effect can be reasonably ignored for most wave-induced seabed responses.

(3) This simulation is mainly limited to wave-induced transient pore- pressure responses in medium and coarse sands. That is, the residual pore-pressure, which usually occurs in very-fine and silty sands (see $[2,28,31]$ ), is beyond the scope of this study. In addition, the model doesn't account for the stress axes rotation under progressive waves [18], which is particularly noteworthy concerning for the residual pore-pressure response.

Governing equations for the poro-elastoplastic seabed are detailed as follows.

The equation of force balance can be expressed as

$\sigma_{\mathrm{ij}, \mathrm{j}}+\rho g_{\mathrm{i}}=0$

where $\sigma_{\mathrm{ij}}$ is the total stress tensor (positive in compression), and subscripts $\mathrm{i}$ and $\mathrm{j}(i, j==1,2)$ indicate the main directions; $g_{\mathrm{i}}$ is the gravitational acceleration in the i-direction; $\rho, \rho_{\mathrm{f}}$ and $\rho_{\mathrm{s}}$ are the density of soil, pore water and soil grains, respectively (note that the relationship exists: $\rho=n \rho_{\mathrm{f}}+(1-n) \rho_{\mathrm{s}}$, in which $n$ is the porosity of the soil).

On the basis of Terzaghi effective stress principle, the total stress can be divided into two components:

$\sigma_{\mathrm{ij}}=\sigma_{\mathrm{ij}}^{\prime}+\delta_{\mathrm{ij}} p$

where $\sigma_{\mathrm{ij}}^{\prime}$ is the effective stress; $\delta_{\mathrm{ij}}$ is the Kronecker delta with 1 for $i==j$ and 0 for $\mathrm{i} \neq \mathrm{j}$; and $p$ is wave-induced pore-pressure in the soil. On the basis of the deformation continuity, the total strain tensor is written in terms of the displacement gradient:

$\varepsilon_{\mathrm{ij}}=\frac{1}{2}\left(u_{\mathrm{i}, \mathrm{j}}^{\mathrm{s}}+u_{\mathrm{j}, \mathrm{i}}^{\mathrm{s}}\right)$

where $\varepsilon_{\mathrm{ij}}$ represents the strain tensor, and $u_{\mathrm{i}}^{\mathrm{s}}$ denotes the soil displacement components.

The elastoplastic constitutive model is adopted for the sandy seabed, which can be expressed in terms of infinitesimal increments:

$d \sigma^{\prime}{ }_{\mathrm{ij}}\left(=D_{\mathrm{ijk}}^{\mathrm{e}} d \varepsilon_{\mathrm{kl}}^{\mathrm{e}}\right)$

$=\left(\lambda \delta_{\mathrm{ij}} \delta_{\mathrm{kl}}+2 G \delta_{\mathrm{ik}} \delta_{\mathrm{jl}}\right)\left(d \varepsilon_{\mathrm{kl}}-d \varepsilon_{\mathrm{kl}}^{\mathrm{p}}\right)$

where $D_{\mathrm{ijkl}}^{\mathrm{e}}$ stands for elements of constitutive matrix that describes the constitutive stress-strain relation; $\lambda=\nu_{\mathrm{s}} E_{\mathrm{s}} /\left[\left(1+v_{\mathrm{s}}\right)\left(1-2 v_{\mathrm{s}}\right)\right]$ is Lame's constant; $G=E_{\mathrm{s}} /\left[2\left(1+v_{\mathrm{s}}\right)\right]$ is the shear modulus of soil; $E_{\mathrm{s}}$ is the elastic modulus of the soil; $\nu_{\mathrm{s}}$ is the Poisson ratio of soil; $\varepsilon_{\mathrm{kl}}^{\mathrm{e}}$ and $\varepsilon_{\mathrm{kl}}^{\mathrm{p}}$ are the elastic and plastic strain vectors, respectively. The plastic strain can be calculated according to the yield function and flow rule of the elastoplastic soil model (see Potts and Zdravkovic [25] for more details).

The Mohr-Coulomb model is utilized to simulate the elastoplastic behavior of the sandy seabed under drained conditions. In such perfectly plastic modeling, no hardening/softening law is required, and the

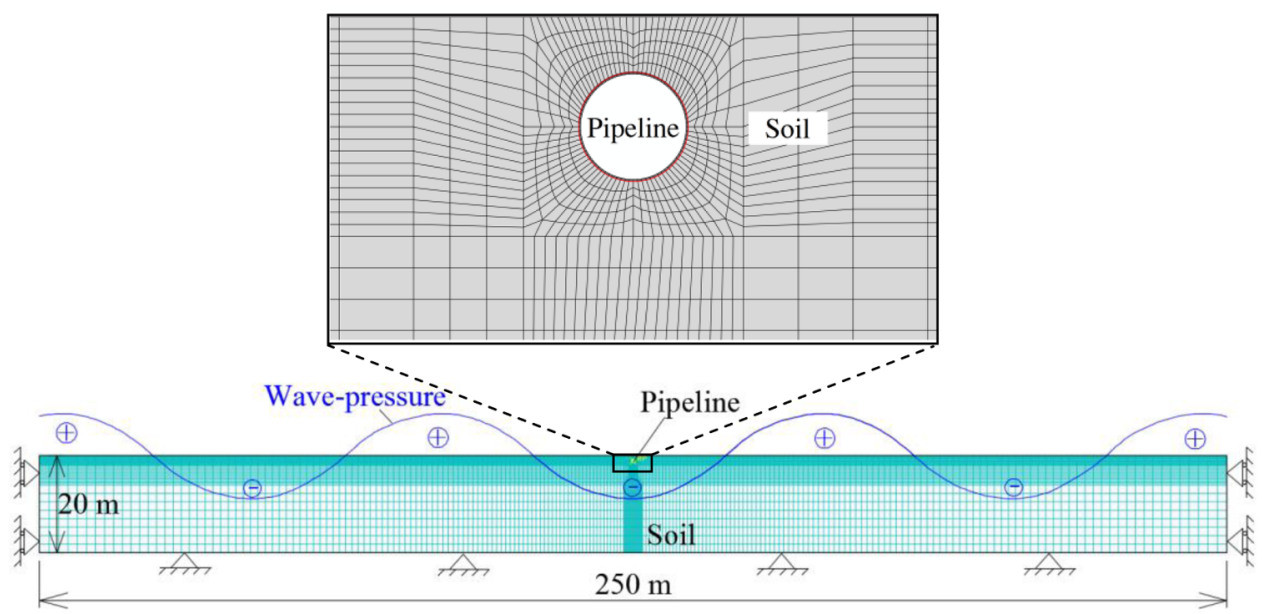

Fig. 2. Meshes and boundary conditions of the numerical model. 
adoption of non-associated flow rule can avoid the pseudo dilation. The yield function of the Mohr-Coulomb model in terms of stress invariants can be expressed as (see [25])

$J-\left(\frac{c}{\tan \phi}+p^{\prime}\right) g(\theta)=0$

in which, $J$ is the deviatoric stress invariant; $c$ is the cohesion strength; $p^{\prime}$ is the mean effective stress;

$g(\theta)=\frac{\sin \phi}{\cos \theta+\sin \theta \sin \phi / \sqrt{3}}$

where $\theta$ is the Lode's angle, and $\phi$ is the peak friction angle of the soil. In the principal effective stress space, the yield function by Eq. (5) is plotted as an irregular hexagonal cone.

Compared with the rigidity of soil, the pipe (commonly using the steel with high Young's modulus $E_{\mathrm{p}}=210 \mathrm{GPa}$, as the primary material) can be reasonably treated as a quasi-rigid body by employing a feature of the software ABAQUS that forces all nodes on the body to move according to displacements and rotations specified at a load reference point. The load reference point is taken at the center of the pipe section.

As aforementioned, the feature of the present model is that the wave-induced transient pore-pressure is included in the background stress field prior to the simulation of pipe-soil interaction. While simulating the wave-induced transient pore-pressure in the porous seabed, the wave-induced seepage flow in the seabed is assumed to obey Darcy's law. On the basis of the conservation of mass, we have

$\frac{k_{\mathrm{s}}}{\gamma_{\mathrm{w}}} \nabla^{2} p=\frac{\partial \varepsilon_{\mathrm{ii}}}{\partial t}+\frac{n}{K^{\prime}} \frac{\partial p}{\partial t}$

where $k_{s}$ is the Darcy's permeability coefficient, which is the same in all the three directions for the isotropic porous seabed; $\gamma_{w}$ is the unit weight of the pore water; $t$ is the time; $K^{\prime}$ is the apparent bulk modulus of pore water; $\varepsilon_{\mathrm{ii}}$ is the volumetric strain of soil. A fully saturated sandy seabed is considered, so the pore water is consequently assumed incompressible. The pore-pressure distribution in a sandy seabed with incompressible pore water is a quasi-static one with no phase shift [7]. The volume strain is always zero for this case, i.e. $\varepsilon_{\mathrm{ii}}=0$ [38]. Therefore, the steady-state coupled pore-pressure/effective stress analysis is adopted in the Abaqus software [16]. The continuation equation (Eq. (7)) can be further simplified as Laplace's equation, i.e.

$\nabla^{2} p=0$

As for the Laplace's equation, both the pore water and soil skeleton are considered as incompressible media. The transient pore-pressure distribution in the porous seabed can be obtained according to Eq. (8) and boundary conditions (see Section 2.4). Compared with Eq. (7), the Laplace's equation could somewhat under-estimate the pore pressure gradients in the seabed under wave loading. Nevertheless, such numerical treatment may provide a fundamentally qualitative estimation of the pore-pressure, and easily achieve the sequential coupling with the plastic-zone development (see Section 4.2).

\subsection{Material properties}

The input data for the numerical simulations are listed in Table 1, including soil properties, wave conditions, and pipe parameters. It has been indicated that the relative density of field sandy backfill material could be very low due to the installation methods such as jet-trenching and ploughing [1]. Nevertheless, continuous wave action can lead to considerable densification, especially in shallow waters [30]. Clukey et al. [5] even reported the values of relative densities up to $90 \%$ due to low-amplitude wave action. A typical value of peak friction angle for loose-to-medium sand, $\phi==30^{\circ}$, is adopted in this study (see [8]). In addition, an upper value of $\phi==45^{\circ}$ for dense sand is also adopted to examine the effect of $\phi$ on the response of uplifted pipes in the parametric study.

A series of trial simulations with various elastic moduli of soil were conducted. The results shows that the elastic modulus of soil only affects the initial stiffness of the curves, but barely has influence on the peak vertical soil resistance. However, the computation time for cases with large elastic moduli of soil (e.g. $E_{s}==50 \mathrm{MPa}$ ) is considerably less than cases with relatively small elastic moduli of soil (e.g. $E_{s}==5 \mathrm{MPa}$ ). The primary focus of this study is to investigate the effects of waves on the peak vertical soil resistance rather than the mobilization distance, or even the exact value of the peak vertical soil resistance. Therefore, a relatively large modulus of soil $E_{s}==50 \mathrm{MPa}$ is adopted in the simulations.

A contact-pair algorithm is adopted to characterize the interfacial constitutive relationship between the pipe exterior surface and its surrounding soil. The Coulomb friction model is used for the frictional interface between the pipe and the soil. The contact surface between the pipe and the soil is regarded to be stable if the frictional shear stress $(\tau)$ is less than the critical one ( $\tau$ crit). Once $\tau$ exceeds $\tau$ crit, slippage along the interface occurs. In the Coulomb friction model, the friction coefficient $(\mu)$ is defined as $\mu==\tan \left(\phi_{\mu}\right)$, where $\phi_{\mu}$ is the friction angle of the pipe-soil interface. The value of $\phi_{\mu}$ can range between $50 \%$ and $100 \%$ of the peak friction angle, depending on the interface characteristics and relative movement between the pipe and the soil [39]. The larger values of $\phi_{\mu}$ are generally associated with rough uncoated pipelines with rusty or corroded surfaces, while the lower values would correspond to pipes with smooth coating. The numerical results of Yimsiri et al. [39] suggested that the surface roughness is insignificant for pipes subjected to upward movement and the results are not particularly sensitive to the choice of $\phi_{\mu}$. A value of $\phi_{\mu}==0.5 \phi$ is herein considered as a reasonable baseline value and adopted in the numerical simulation presented in this paper.

\subsection{Boundary conditions}

As shown in Fig. 2, on the lateral boundaries, the normal component of displacement is fixed, and no flow of pore fluid through the walls is permitted. At the bottom of the model, the translational degrees of freedom in two directions are fixed. The top surface of the seabed has no constraints of the soil displacements and allows perfect drainage.

The user subroutines are used to load the wave pressure at the seabed surface. This approach has been proved to be feasible in the existing numerical studies (e.g., [34]). The wave pressure acting on the seabed surface is applied by the subroutine DLOAD, whereas the wave pressure at the seabed surface is loaded by the subroutine DISP. It is assumed that the wave-induced shear stress is small and negligible at the surface of the seabed $[20,40]$. Therefore, the wave pressure is equal to the pore-pressure at the mudline. The wave pressure at the mudline $p_{0}$ can be expressed as

Table 1

Input data for seabed, wave and pipeline.

\begin{tabular}{lll}
\hline & Parameters & Values \\
\hline \multirow{2}{*}{ Seabed } & Peak friction angle $(\phi)$ & $30^{\circ}$ (various in Section 4.3) \\
& Elastic modulus of soil $\left[E_{\mathrm{s}}(\mathrm{MPa})\right]$ & 50.0 (various in Section 4.3) \\
& Poisson ratio of soil $\left[\nu_{\mathrm{s}}\right]$ & 0.30 (various in Section 4.3) \\
& Submerged unit weight of soil $\left[\gamma^{\prime}\left(\mathrm{kN} / \mathrm{m}^{3}\right)\right]$ & 7.84 \\
& Cohesion strength $[c(\mathrm{kPa})]$ & 0 \\
& Seabed thickness $\left[d_{0}(\mathrm{~m})\right]$ & 20.0 \\
Wave & Water depth $[h(\mathrm{~m})]$ & 12.0 (various in Section 4.2) \\
& Wave period $[T(\mathrm{~s})]$ & 7.0 (various in Section 4.2$)$ \\
\multirow{5}{*}{ Pipeline } & Wave height $[H(\mathrm{~m})]$ & 2.0 (various in Section 4.2) \\
& Young's modulus $\left[E_{\mathrm{p}}(\mathrm{GPa})\right]$ & 210 \\
& Poisson ratio $\left[\nu_{\mathrm{p}}\right]$ & 0.19 \\
& Diameter $[D(\mathrm{~m})]$ & 1.0 \\
& Burial-depth $[d(\mathrm{~m})]$ & 0.5 \\
\hline
\end{tabular}


$p_{0}=P_{0} \cos (k x-\omega t)$

where $P_{0}\left(=\frac{\rho_{\mathrm{f}} g H}{2 \cosh (k h)}\right)$ is the amplitude of the wave pressure at the mudline, based on Airy's linear wave theory; $g$ is the gravitational acceleration; $k(==2 \pi / L)$ is the wave number; $L$ is the wave length, and $\omega$ is the angular frequency of the wave. Note that, in shallow waters, the wave profile normally has steep crest and flat trough, resulting from the non-linearity of waves. Under nonlinear wave conditions, the thirdorder approximation of non-linear wave theory can be employed for calculating the wave pressure at the mudline (see [15]).

\subsection{Loading procedures}

Three loading steps are utilized in the numerical modeling process:

Step-1: Generation of initial geostress. The initial geostress $\left(\gamma^{\prime} z\right)$ is firstly generated by exerting a uniform body force on the seabed. A technique named as "equilibrium of geostress" is adopted to eliminate the fake displacement in the soil while generating the initial geostress.

Step-2: Simulation of transient pore-pressure. The wave pressure is then applied onto the seabed surface for simulating the transient pore-pressure distribution around the buried pipe in the porous soil (see Fig. 3). Note that under wave troughs or wave crests, the waveinduced seepage forces in the soil are upward or downward, respectively. But the former scenario is much more critical for vertical pipe-soil interactions.

Step-3: Exertion of an uplift load: After the background stress fields are set up successively, i.e. the initial geostress (by Step-1) and the transient pore-pressure (by Step-2), an upward concentrated force is gradually exerted onto the buried pipe under the quasi-static loading condition. The poro-elastoplastic responses during the vertical pipe-soil interaction can be simulated numerically.

Note that in the present numerical model, the pore-pressure surrounding the pipe periphery cannot be directly exerted on the pipe in Step- 2 and thus only the effective stress is transmitted between the pipe periphery and surrounding soil. The wave-induced additional uplift force is included in the externally exerted concentrated force on the pipe (see Step-3). Therefore, the vertical soil resistance is equal to the externally exerted concentrated force on the pipe (no pipe weight is exerted in Step-1).

\section{Verification}

As aforementioned, the proposed plane-strain poro-elastoplastic model is capable of sequentially simulating the pore-pressure generation in a sandy seabed under waves and the plastic-zone development while uplifting the pipe. The numerical model mainly comprises two sub-models: one is the seabed-pipeline interaction model; the other is the wave-seabed interaction model for simulating wave-induced porepressure in the seabed. To the authors' knowledge, no experimental results are available to date concerning the influence of wave-induced pore-pressure on the uplift soil resistance to a buried pipe. The two sub- models are verified against experimental results and analytical solutions, respectively.

Trautmann et al. [32] performed pipe-soil interaction tests to investigate the pipeline behavior subjected to lateral and upward movements. The peak vertical soil resistances produced by the present seabed-pipeline interaction model are compared here against the experimental measurements of Trautmann et al. [32] and the predictions using DNV GL method [10] to examine the capability of the current numerical model. The tests were carried out in a specially-designed tank of $1.2 \mathrm{~m}$ (width) $\times 2.3 \mathrm{~m}$ (length) $\times 1.5 \mathrm{~m}$ (depth). The steel pipe section used for the tests has an outside diameter of $102 \mathrm{~mm}$, a wall thickness of $6.4 \mathrm{~mm}$, and a length of $1.20 \mathrm{~m}$. The burial-depth of pipe (measured to the top of pipe) is $0.357 \mathrm{~m}$. Cornell filter sand was used for all the tests. It is a clean, subangular, fluvioglacial sand, having a coefficient of uniformity $C_{\mathrm{u}}$ of 2.6 and an effective grain size $D_{10}$ of $0.2 \mathrm{~mm}$. The input values of soil properties for the numerical model are in accordance with Trautmann et al. [32] and Yimsiri et al. [39]. For the case of medium sand, the main soil parameters are as follow: $\phi==35^{\circ}$, dilation angle $\psi==5^{\circ}, E_{\mathrm{s}}==3.0 \mathrm{MPa}, \nu_{s}==0.3$, $\gamma_{\mathrm{d}}=16.4 \mathrm{kN} / \mathrm{m}^{3}$ and $c==0$. For the case of dense sand, the main soil parameters are $\phi==44^{\circ}, \psi==16^{\circ}, E_{\mathrm{s}}==3.65 \mathrm{MPa}, \nu_{s}==0.3$, $\gamma_{\mathrm{d}}=17.7 \mathrm{kN} / \mathrm{m}^{3}$ and $c==0$. The input values for the other four cases between medium sand and dense sand are interpolated by assuming linear dependences on $\phi$.

According to Det Norske Veritas and Germanischer Lloyd [10], the peak vertical soil resistance to a buried pipe was expressed as

$F_{\text {rp }}=\gamma^{\prime} d D+\gamma^{\prime} D^{2}\left(\frac{1}{2}-\frac{\pi}{8}\right)+f \gamma^{\prime}\left(d+\frac{D}{2}\right)^{2}$

where $f$ is the vertical soil resistance factor. An empirical model based on the peak friction angle for the low estimate value of $f$ was provided as follow

$f= \begin{cases}0.1 & \text { for } \phi \leq 30^{\circ} \\ 0.1+\frac{\phi-30}{30} & \text { for } 30^{\circ}<\phi \leq 45^{\circ} \\ 0.6 & \text { for } \phi>45^{\circ}\end{cases}$

Best estimate and high estimate of $f$ can be determined by adding 0.19 and 0.38 respectively to the low estimate values. According to the test conditions of Trautmann et al. [32], the value of $\gamma_{d}$ varies from $16.4 \mathrm{kN} / \mathrm{m}^{3}$ for medium sand $\left(\phi==35^{\circ}\right)$ to $17.7 \mathrm{kN} / \mathrm{m}^{3}$ for dense sand $\left(\phi==44^{\circ}\right)$. The input value of $\gamma^{\prime}$ for the DNV GL method (Eq. (10)) is interpolated by assuming a linear dependence on $\phi$.

Fig. 4 shows the comparison of the peak vertical soil resistance among the present numerical model, the tests of Trautmann et al. [32] and the DNV GL method. A fair match is indicated between the present numerical results and the experimental measurements for both medium and dense sand. The data points of experimental and numerical results generally distribute around the best estimate of the DNV GL method. A consistent trend of increasing $F_{\mathrm{rp}}$ with increasing $\phi$ can be clearly observed. The present seabed-pipeline interaction model is proved feasible for predicting the peak vertical soil resistance. It should be noted that all the results in Fig. 4 were obtained without considering the wave effects. The peak vertical soil resistance would be overestimated by the

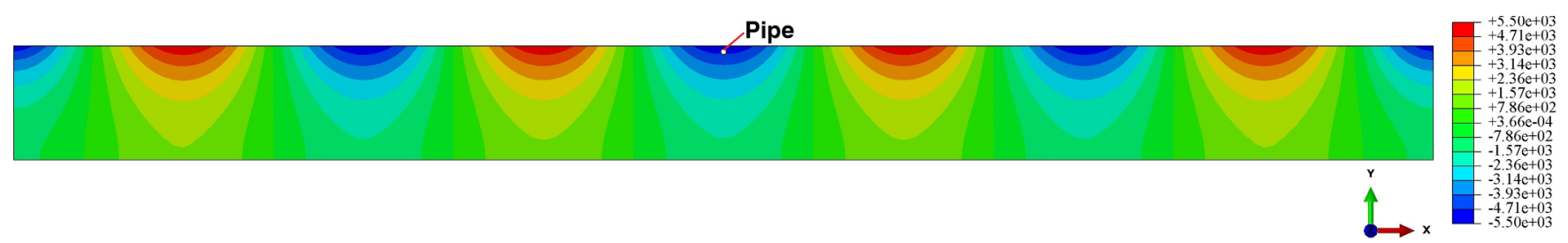

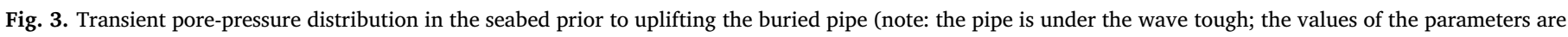
given in Table 1). 


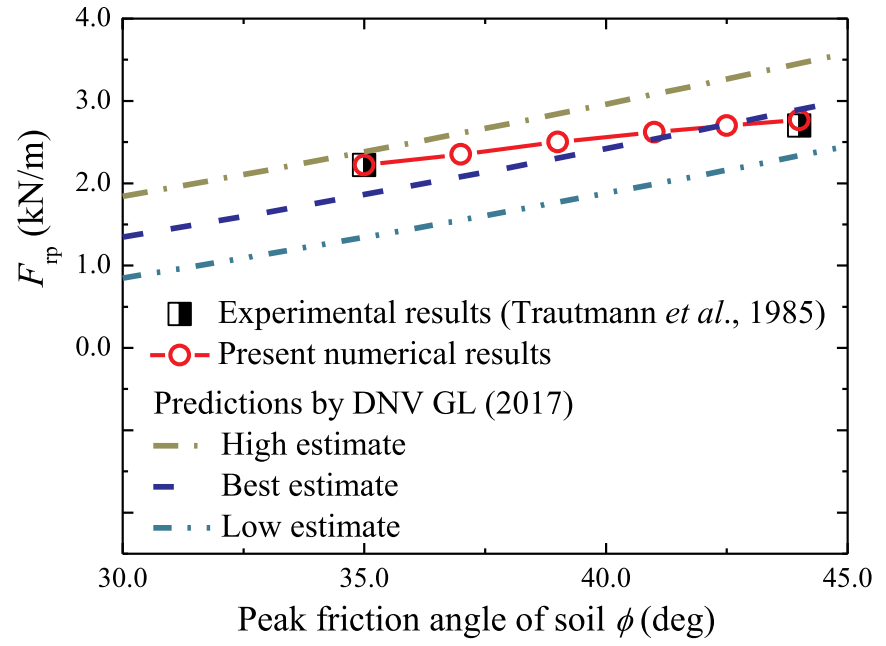

Fig. 4. Peak vertical soil resistance to the buried pipe vs peak friction angle (without wave effects).

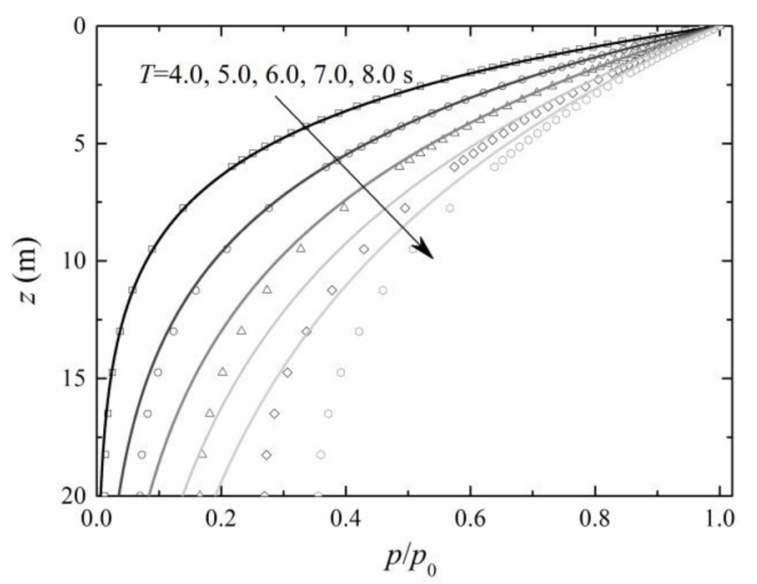

Fig. 5. Comparison of normalized wave-induced far-field pore-pressure $\left(p / p_{0}\right)$ along soil depth under wave troughs between the present model and analytical solutions of Yamamoto et al. [38] (the solid lines represent analytical solutions and the scattered points denote numerical results; the values of the parameters except $T$ are given in Table 1 ).

conventional DNV GL method if the progressive waves are involved.

Fig. 5 presents a comparison of normalized wave-induced porepressure $\left(p / p_{0}\right)$ distributions in a saturated sandy seabed under wave troughs between the present numerical model and analytical solutions

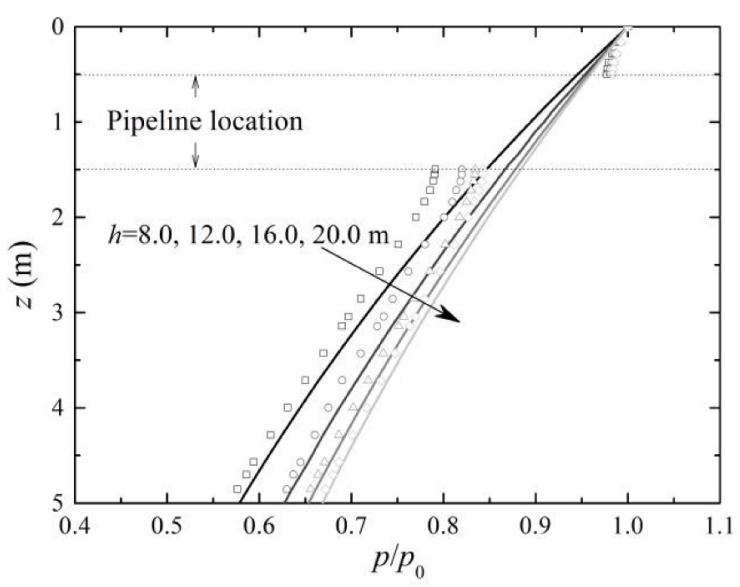

(a)

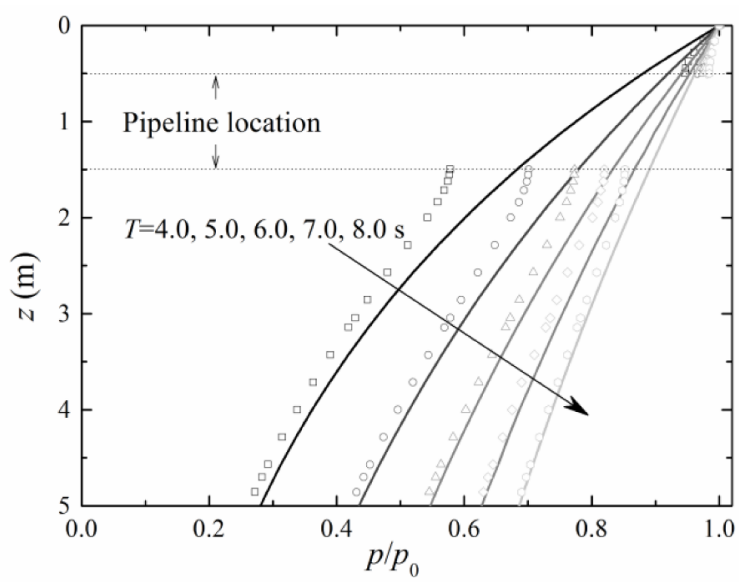

(b)

Fig. 7. Comparison of the normalized peak values of the wave-induced porepressure $\left(p / p_{0}\right)$ along soil depth under wave troughs in far-field and through the center of the pipe for various (a) water depths; and (b) wave periods (the values of the parameters except $h$ and $T$ are given in Table 1).

proposed by Yamamoto et al. [38]. It is indicated that the results of the present numerical model generally agree well with the analytical ones. Some deviation exists in the lower part of the seabed with increasing wave period. This deviation can be explained as follow: with increasing wave period, the ratio of wave length to seabed thickness increases and

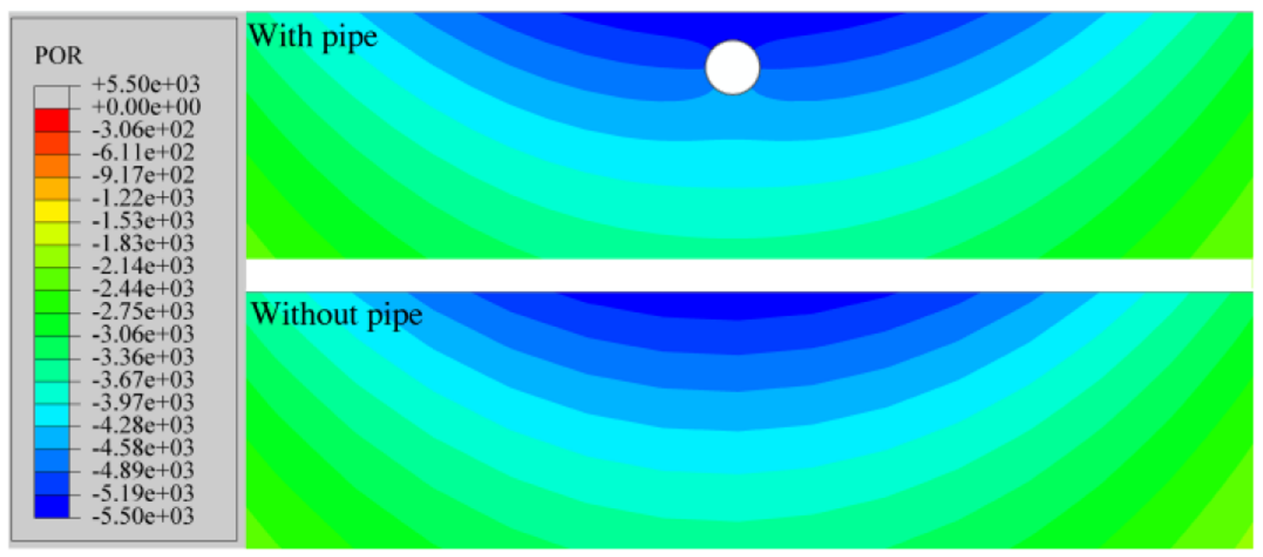

Fig. 6. Comparison of wave-induced pore-pressure at wave trough between the cases with and without a pipe (the values of the parameters are given in Table 1). 


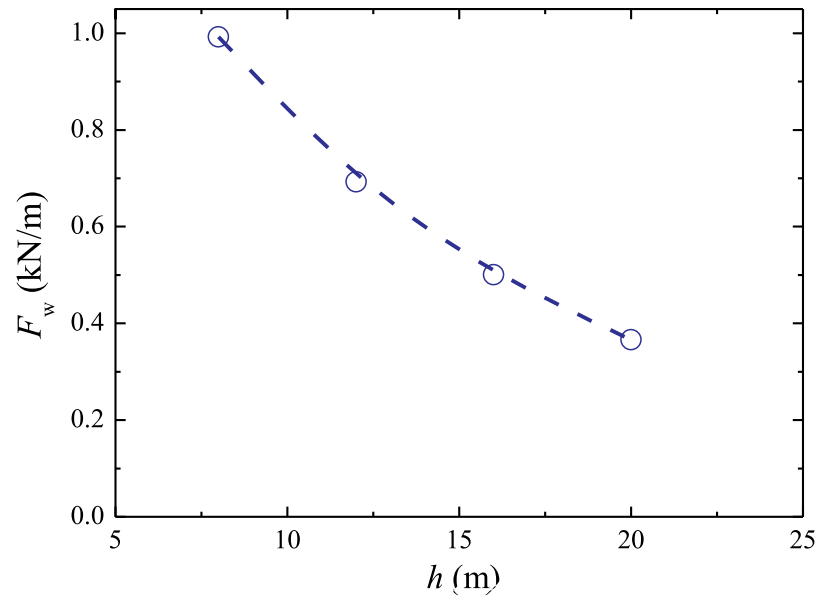

(a)

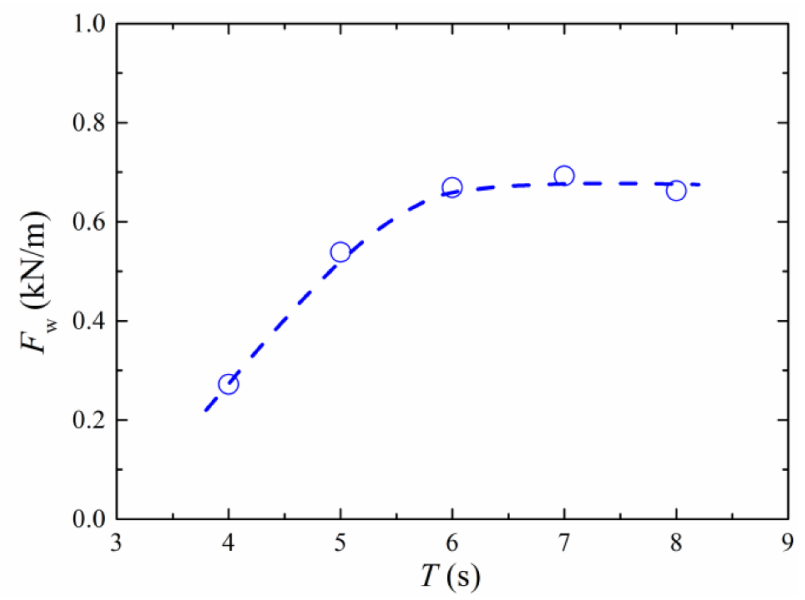

(b)

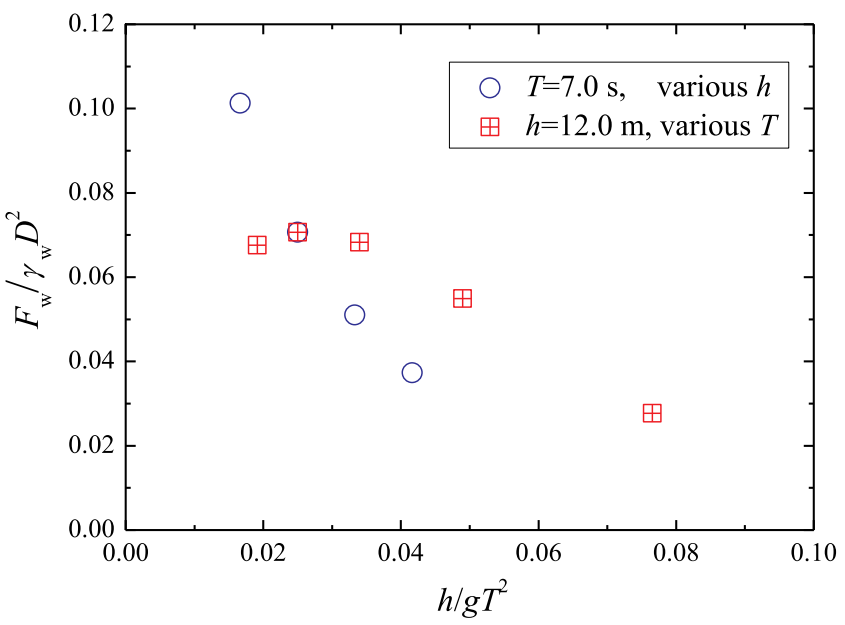

(c)

Fig. 8. Variations of (a) $F_{\mathrm{w}}$ with water depth; (b) $F_{\mathrm{w}}$ with wave period; and (c) the normalized uplift force $\left(F_{\mathrm{w}} / \gamma^{\prime} D^{2}\right)$ with $h / g T^{2}$ (the values of the parameters except $h$ and $T$ are given in Table 1$)$.

the assumption of infinite thickness of seabed in the analytical solutions doesn't hold true anymore, inevitably causing some errors (refer to [17]). It should be noted that good consistency between the present numerical and analytical results is always observed in the upper part (e.g., $z<5.0 \mathrm{~m}$ ), where the examined pipe is located.

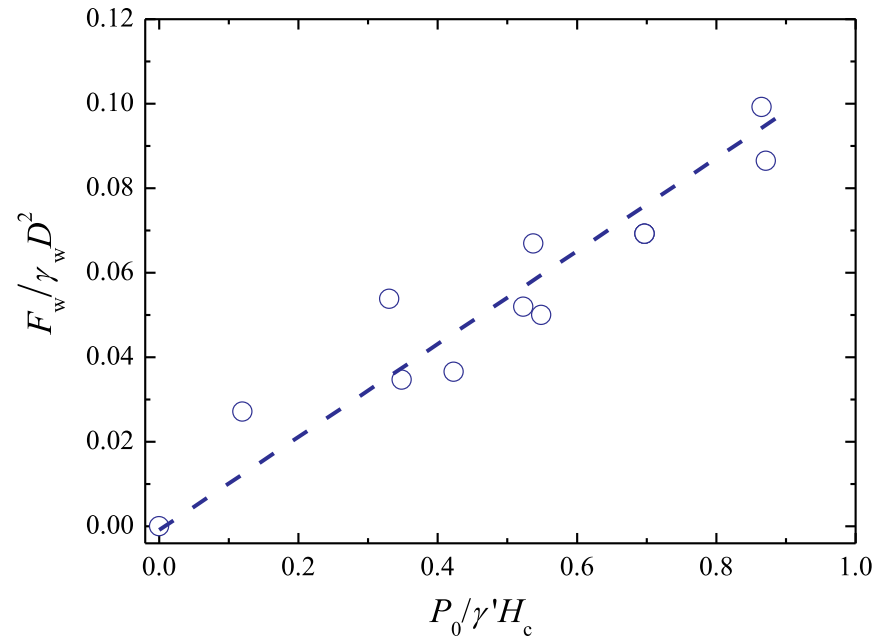

Fig. 9. Variation of the normalized uplift force $\left(F_{\mathrm{w}} / \gamma_{\mathrm{w}} D^{2}\right)$ with the normalized amplitude of wave -pressure at the mudline $\left(P_{0} / \gamma^{\prime} H_{\mathrm{c}}\right)$.

\section{Parametric study and discussions}

The above FEM model is used to investigate the effects of variable parameters of wave and soil on the wave-soil-pipe interaction. The input data for the investigations are listed in Table 1.

\subsection{Pore-pressure response around the pipe and resultant uplift force}

Under wave troughs, the wave-induced pore-pressure response along the periphery of pipe will result in an uplift force $F_{w}$ acting on the buried pipe. In this section, the pore-pressure response and uplift force are analyzed for various values of wave period and water depth.

Fig. 6 shows a comparison of the wave-induced pore-pressure contour between the cases with and without a pipe under the wave trough in the seabed. It can be seen that the existence of the pipe alters the pore-pressure distribution obviously in its vicinity.

To quantitatively evaluate the perturbation effect of a buried pipe on the pore-pressure distribution in the surrounding soil, distributions of the normalized wave-induced pore-pressure $\left(p / p_{0}\right)$ along the soil depth in far-field and through the center of the pipe for various water depths and wave periods are compared in Fig . 7(a) and (b), respectively. Fig. 7 indicates that the pipe has a sheltering effect on the porepressure transmission. Specifically, the value of the excess pore-pressure $\left(p-p_{0}\right)$ is smaller at the pipe top and larger at the pipe bottom than the same depth of far field zone under wave troughs. Therefore, the perturbation effect of the pipe on the original pore-pressure distribution in the soil will render the uplift force significantly larger than the nonperturbed one, which is consistent with the conclusion of Magda [23].

For the fully saturated sandy seabed in the present study, the vertical pore-pressure profile normalized with pore-pressure at the mudline $\left(p / p_{0}\right)$ is practically controlled by the wave number $\lambda$ (see [38]). Both water depth and wave period can affect the profile of $p / p_{0}$ by influencing the value of wave length. By comparing Fig. 7(a) with (b), it can be seen that increasing both water depth and wave period are beneficial to the transmission of pore-pressure, and the effect of wave period on the normalized vertical pore-pressure profile gets more significant. It should be noted that both water depth and wave period also affect the amplitude of the pore-pressure at the mudline $P_{0}$. Specifically, increasing water depth can result in a smaller value of $P_{0}$ while increasing wave period can induce a larger one. While evaluating the effects of water depth and wave period on the uplifted pipe response, the specific values of the excess pore-pressure in the seabed under wave troughs $P_{0}\left(1-p / p_{0}\right)$ are the primary concern and concurrently influenced by $P_{0}$ and $p / p_{0}$. 


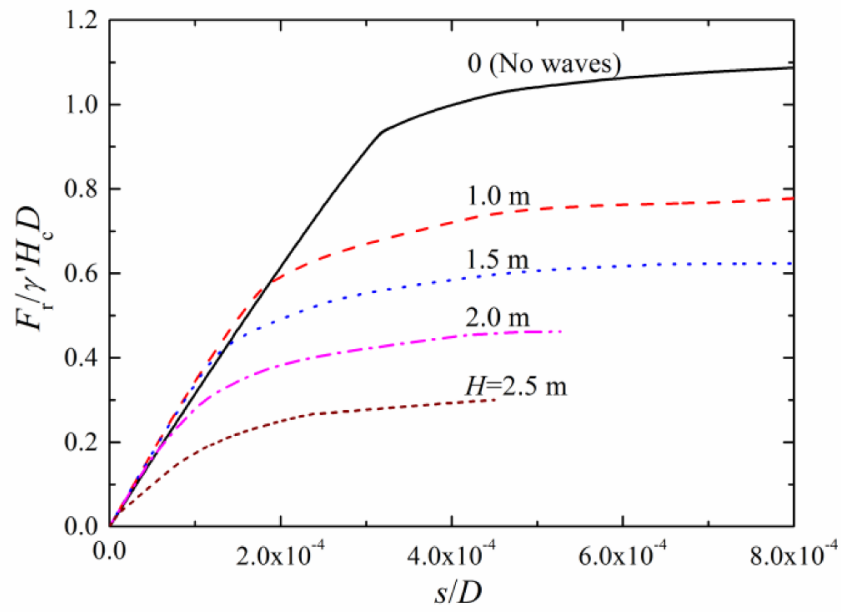

(a)

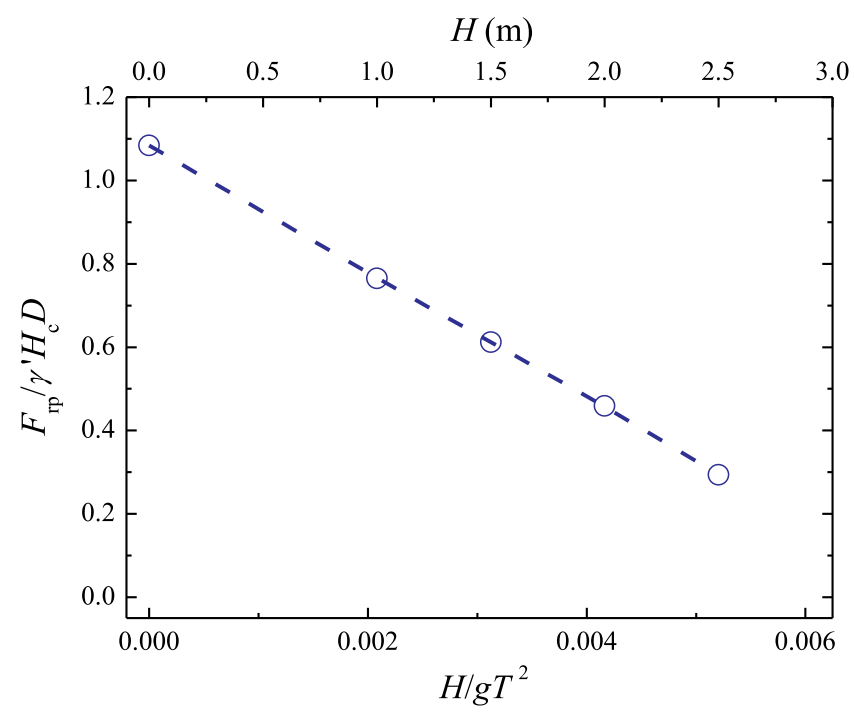

(b)

Fig. 10. Effects of wave height on (a) the normalized force-displacement curves; and (b) the normalized peak vertical soil resistance of the buried pipeline (the values of the parameters except $H$ are given in Table 1).

The pore-pressure distribution along the pipe periphery is extracted and integrated to obtain the wave-induced uplift force under wave troughs $F_{\mathrm{w}}$. The variations of $F_{\mathrm{w}}$ with water depth and wave period are given in Fig. 8(a) and (b), respectively. The value of $F_{\mathrm{w}}$ decreases with increasing water depth. With increasing wave period, the value of $F_{\mathrm{w}}$ increases first, then reaches a maxima at wave period around $6 \mathrm{~s}$ and generally keeps constant. The results in Fig. 8(a) and (b) are normalized and shown in Fig. 8(c) together. The non-dimensional parameter $h / g T^{2}$ reflects the relative quantity of water depth to wave length. The values of $F_{\mathrm{w}}$ are normalized by the displaced water weight of the pipe. As shown in Fig. 8(c), the normalized uplift force generally decreases with increasing value of $h / g T^{2}$.

For the examined conditions, although the maximum magnitude of $F_{\mathrm{w}}$ is only approximately less than $13 \%$ of the displaced water weight of the pipe (i.e. $F_{\mathrm{w}}<0.13\left(\frac{\pi}{4} \gamma_{\mathrm{w}} D^{2}\right)$ ), the uplift force could still significantly affect the vertical on-bottom stability of pipelines. This is because that the vertical soil resistance would also be small and thus comparable to $F_{\mathrm{w}}$ for the conditions under which the largest $F_{\mathrm{w}}$ occurs.

For a fixed value of burial-depth, the uplift force on a pipe in the saturated sandy seabed is mainly dependent on the amplitude of porepressure at the mudline $P_{0}$ and the wave length $L$. The variation of the normalized uplift force $F_{\mathrm{w}} / \gamma_{\mathrm{w}} D^{2}$ with normalized amplitude of wave pressure at the mudline $P_{0} / \gamma^{\prime} H_{\mathrm{c}}$ is shown in Fig. 9. The value of $P_{0} / \gamma^{\prime} H_{\mathrm{c}}$ indicates the ratio of the amplitude of wore-pressure at the mudline to the vertical effective stress at the depth of pipe center. The value of $F_{\mathrm{w}} /$ $\gamma_{\mathrm{w}} D^{2}$ generally increases linearly with $P_{0} / \gamma^{\prime} H_{\mathrm{c}}$, implying the controlling role of $P_{0}$ in determining $F_{\mathrm{w}}$. For the other values of burial-depth, this conclusion needs to be further verified.

\subsection{Effects of wave parameters}

In order to investigate the effects of wave parameters on the response of uplifted pipes, the values of wave height, water depth, and wave period are varied individually, while the other parameters remaining constant (see Table 1).

Fig. 10(a) shows the normalized force-displacement curves under various wave heights. The uplift force $F_{\mathrm{rp}}$ is normalized by the weight of the rectangular soil block above the center of pipe (refer to [1]) and the displacement of the pipe $s$ is normalized by the pipe diameter hereinafter. It is shown that with increasing wave height, the curves gradually shift downwards. The normalized peak vertical soil resistance under wave troughs $F_{\mathrm{rp}} / \gamma^{\prime} H_{\mathrm{c}} D$ ( $H_{\mathrm{c}}$ is the burial-depth to the center of pipe) is gathered from the plateau of the force-displacement curves and shown in Fig. 10(b). The scale of non-dimensional wave height $H / g T^{2}$ is also shown in the top axis. The non-dimensional parameter $H / g T^{2}$ reflects the relative quantity of wave height to wave length. The value of the normalized peak vertical soil resistance decreases approximately linearly with increasing wave height. Specifically, normalized peak vertical soil resistance is approximately halved by a wave of $H==1.5 \mathrm{~m}$.

Plastic strain contours of soils around the pipe at the moment of pipe losing its vertical stability under various wave heights are shown in Fig. 11. It's clearly shown that for all the examined cases, a pair of nearly vertical shear bands can be found along the shoulders of the pipe, which generally coincide with the vertical slip model (refer to [35]). As wave height increases, the zone with relatively large plastic strain shrinks, i.e., vertical instability of pipe occurs while less plastic strain is mobilized. For the cases of no waves, the overburden soils above the pipe between the pair of shear bands generally all deform with significant plastic strain. With the increase of wave height, a pair of soil bands (originating from the top of the pipe and obliquely extend to the soil surface) which only have negligible plastic strain gradually emerge. In other words, the plastic strain in the overburden soil above the pipe is becoming localized due to the effect of wave-induced porepressure in the seabed.

Two normalized force-displacement curves for $H==0$ (no waves) and $H==2.0 \mathrm{~m}$ are specially compared in Fig. 12. The evolutions of plastic zones in the soils around the pipe at different stages of the two curves are given. For the case of no waves, the plastic zone in the overburden soils initiates from the upper part of the pipe surface, then gradually expands horizontally to the two side points of the pipe and vertically to the soil surface. In contrast, for the case of $H==2.0 \mathrm{~m}$, the plastic zone in the overburden soils initiates from the shoulders of the pipe and develops into a pair of vertical soil blocks containing significant plastic strain as vertical uplift force increases.

The effects of water depth and wave period on the response of uplifted pipelines are shown in Figs. 13 and 14, respectively. As shown in the Figs. 13(a) and 14(a), the plateau stage of the normalized forcedisplacement curves emerges earlier with decreasing water depth and increasing wave period. The value of normalized peak vertical soil resistance thus decreases with decreasing water depth and increasing wave period (see Figs. 13(b) and 14(b)).

As aforementioned, the effects of decreasing water depth on both wave length and amplitude of pore-pressure at the mudline are beneficial to the occurrence of larger excess pore-pressure in the shallow zone of seabed, which would result in more reduction of peak vertical 


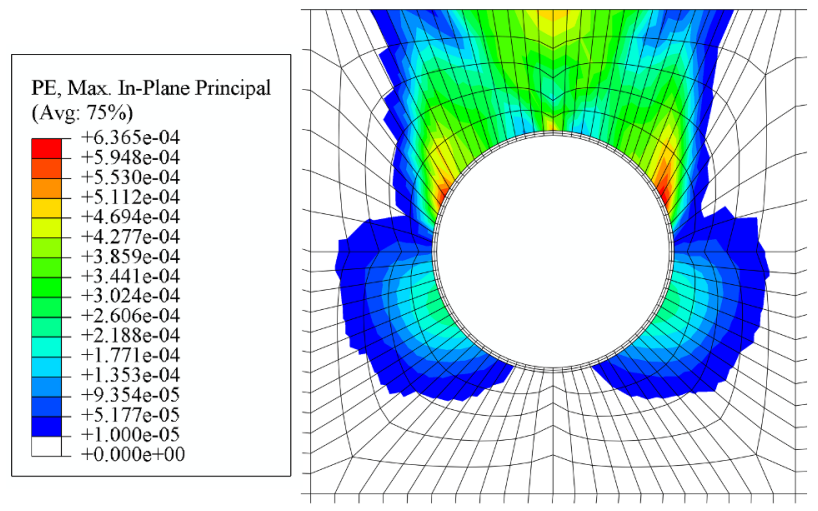

(a)

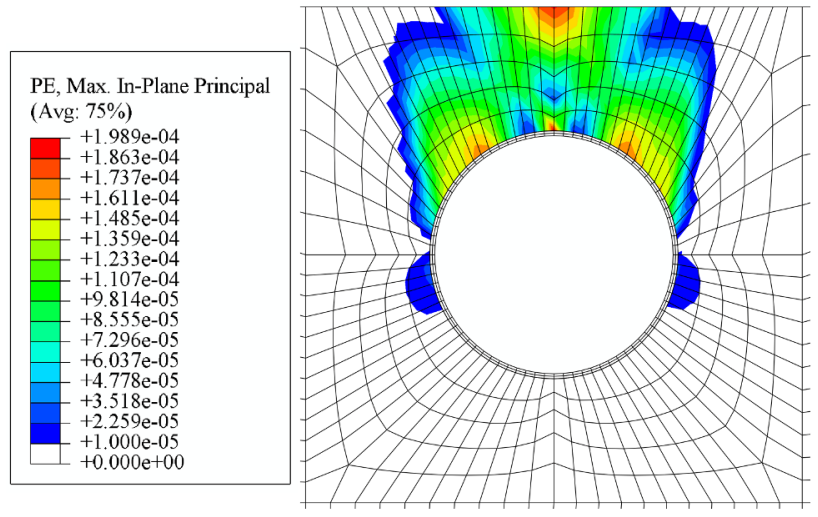

(c)

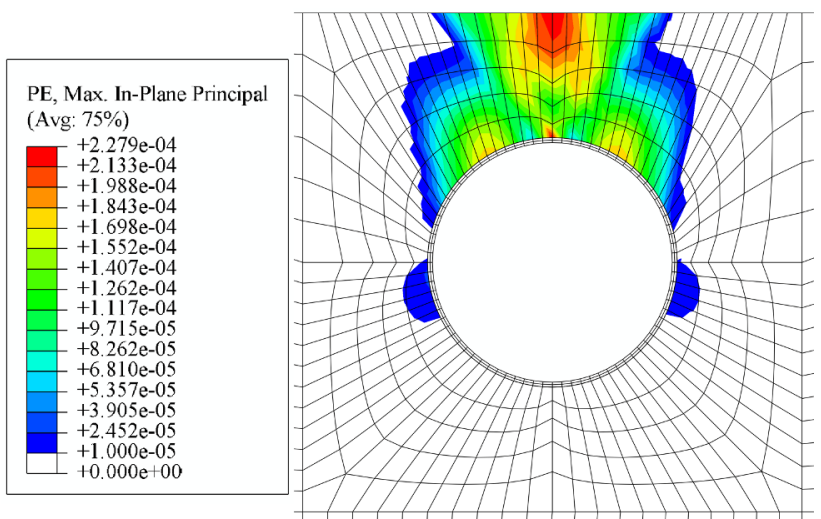

(b)

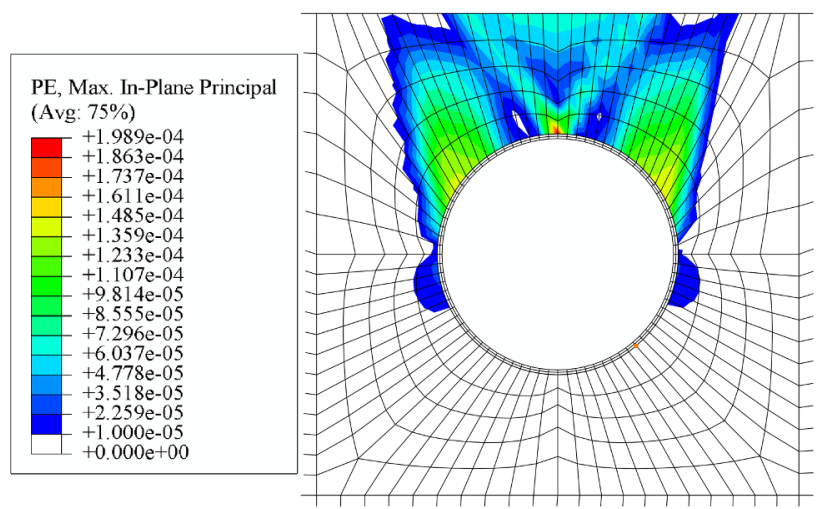

(d)

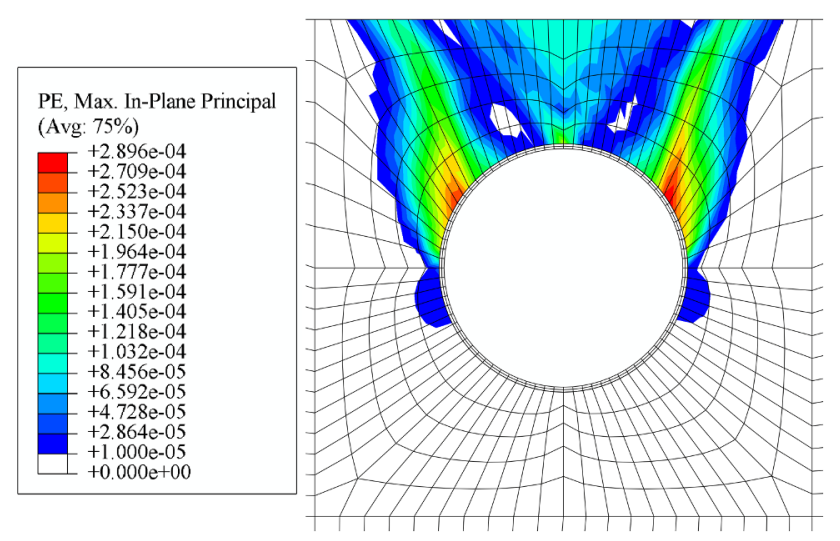

(e)

Fig. 11. Plastic strain contours of soils around the buried pipe while losing vertical stability for various wave heights: (a) $H==0$ (no waves); (b) $H==1.0 \mathrm{~m}$; (c) $H==1.5 \mathrm{~m}$; (d) $H==2.0 \mathrm{~m}$; (e) $H==2.5 \mathrm{~m}$ (the values of the parameters except $H$ are given in Table 1).

soil resistance. In contrast, for increasing wave period, only the induced larger amplitude of pore-pressure at the mudline is beneficial to the reduction of peak vertical soil resistance. The significant decrease of normalized peak vertical soil resistance with $T$ shown in Fig. 14(b) indicates that the effects of enlarged amplitude of pore-pressure at the mudline are in control rather than the effects of increasing wave length.

\subsection{Effects of seabed properties}

For the fully saturated sandy seabed, wave-induced pore-pressure response in the seabed is independent of the permeability of the soil (see [38]). Therefore, only the effects of peak friction angle, elastic modulus of soil and Poisson ratio of soil are investigated whilst the effects of soil permeability are not included.

Fig. 15 shows the normalized force-displacement curves and corresponding normalized peak vertical soil resistance for two different peak friction angles with various wave heights. It's indicated that the initial stiffness of the force-displacement curves is not affected by the peak friction angle. The normalized peak vertical soil resistance is obviously increased by a larger peak friction angle. Nevertheless, Fig. 15(b) indicates that the relative reduction of normalized peak vertical soil resistance induced by wave-induced pore-pressure under 


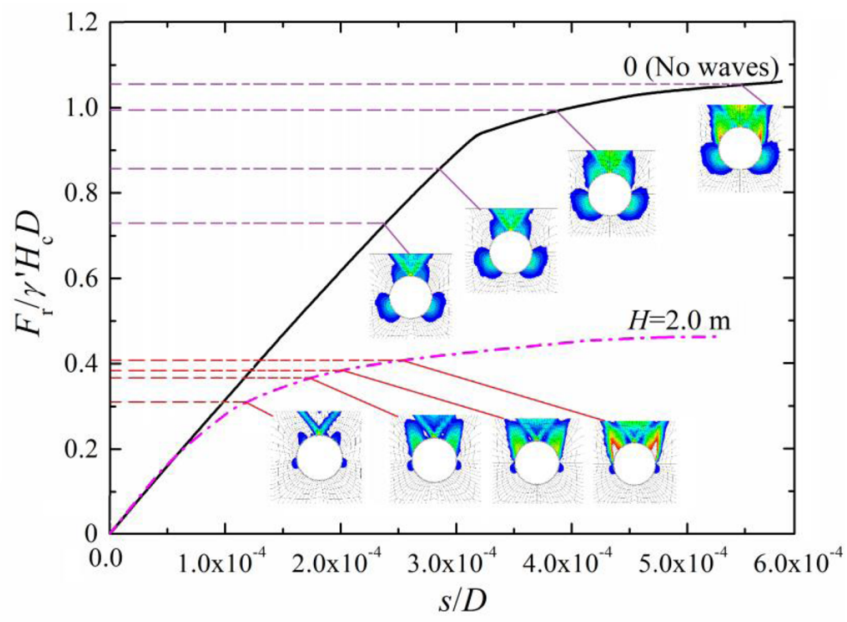

Fig. 12. Comparisons of normalized force-displacement curves and the evolution of plastic zones between cases of $H==0$ (no waves) and $H=2.0 \mathrm{~m}$ (the values of the other parameters are given in Table 1).

certain wave conditions keeps unchanged for different peak friction angles (refer to Fig. 19).

Fig. 16 gives the comparison of the normalized force-displacement curves under different elastic moduli of soil. In contrast to the effects of peak friction angle, the elastic modulus of soil only affects the initial stiffness of the curves while the normalized peak vertical soil resistance generally keeps constant. It can be concluded that for a shallowlyburied pipe in saturated sands, while evaluating the relative reduction of peak vertical soil resistance resulted from wave-induced pore-pressure, the effects of soil parameters (peak friction angle and elastic modulus of soil) can be neglected and only the wave parameters should be considered (refer to Fig. 19).

The Poisson ratio of soil mainly affects the lateral initial geostress $\left(\sigma_{h}=K_{0} \gamma^{\prime} z\right)$ via its correlation with the coefficient of earth pressure at rest $\left(K_{0}\right)$, i.e. $K_{0}=v_{\mathrm{s}} /\left(1-v_{\mathrm{s}}\right)$. The variation range of $K_{0}$ for typical sands is approximately 0.3-0.6 (see [6]). Three typical values of the Poisson ratio of sands, $\nu_{s}==0.23,0.30$, and 0.375 (corresponding to $K_{0}=0.3$, 0.43 and 0.6 , respectively), are adopted to investigate the effect of $v_{\mathrm{s}}$ or $K_{0}$ on the response of uplifted pipes.

Fig. 17 compares the normalized force-displacement curves and corresponding normalized peak vertical soil resistance with and without wave effects for three typical values of the Poisson ratio of soil. It is shown that the initial stiffness of the force-displacement curves is not affected by the Poisson ratio of soil. The normalized peak vertical soil resistance increases with increasing Poisson ratio of soil for conditions both with and without waves. With respect to the wave effects on the peak vertical soil resistance, Fig. 17(b) indicates that the relative reduction of normalized peak vertical soil resistance induced by waveinduced pore-pressure under certain wave conditions generally remains the same for different Poisson ratio of soil (refer to Fig. 19).

\subsection{Resistance-reduction coefficient}

For a pipe buried in saturated seabed, the peak vertical soil resistance would vary sinusoidally under the action of waves (see Fig. 18). While the pipe center locates exactly under wave trough, the peak vertical soil resistance reaches the minimum during a wave period. The peak vertical soil resistance under wave troughs $\left(F_{\mathrm{rp}}\right)$ corresponds to the most critical scenario involving the vertical buckling of buried pipelines. To qualitatively characterize the influence of wave loading on the vertical soil resistance to a burial pipe, a resistance-reduction coefficient $(\eta)$ is introduced:

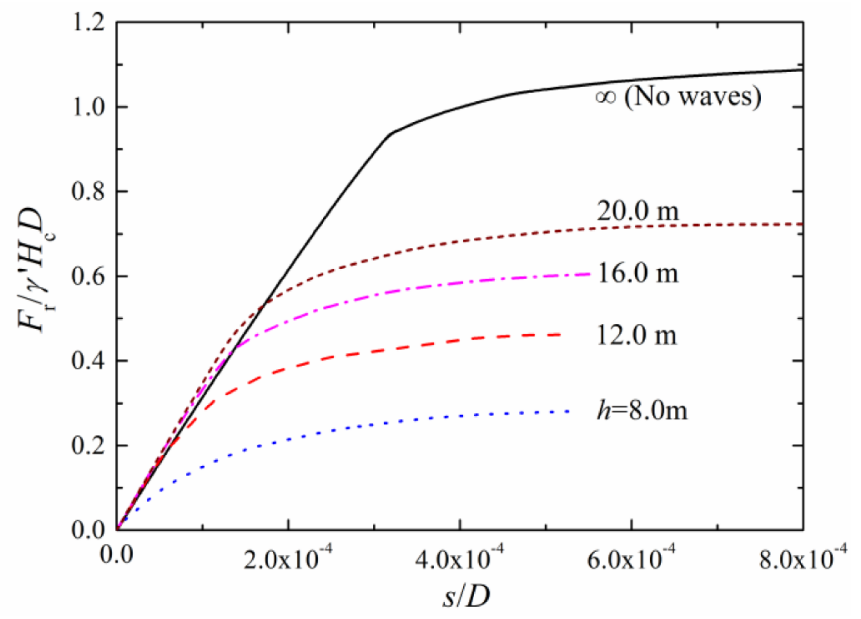

(a)

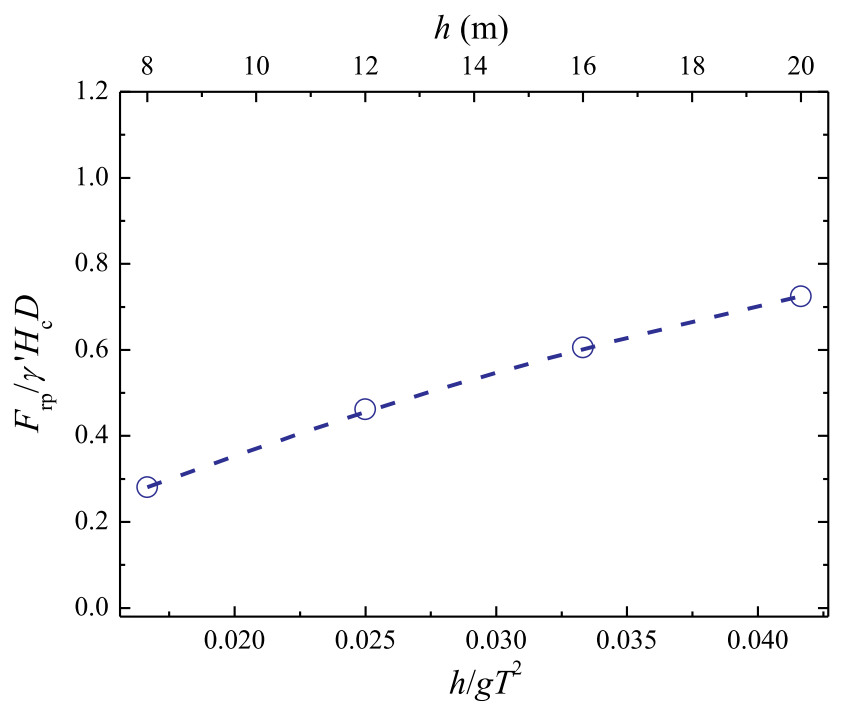

(b)

Fig. 13. Effects of water depth on (a) the normalized force-displacement curves and (b) normalized peak vertical soil resistance of the buried pipeline (the values of the parameters except $h$ are given in Table 1).

$\eta=\frac{F_{\mathrm{rp}}}{F_{\mathrm{rp} 0}}$

which is the ratio of peak vertical soil resistance to a buried pipe under wave troughs $\left(F_{\mathrm{rp}}\right)$ to that without waves $\left(F_{\mathrm{rp} 0}\right)$.

Fig. 19 gives the variation of $\eta$ with the normalized amplitude of wave pressure at the seabed mudline $\left(P_{0} / \gamma^{\prime} H_{c}\right)$, which is on the basis of the present numerical results of 16 cases under the condition of $d /$ $D==0.5$. As aforementioned, the value of $P_{0} / \gamma^{\prime} H_{\mathrm{c}}$ indicates the ratio of the amplitude of pore-pressure at the mudline to the vertical effective stress at the depth of pipe center. It is found that for the examined various wave and soil parameters as listed in Table 1 , all the data generally distribute around an unified line, which can be formulated with the following empirical expression:

$\eta=1.0-0.82\left(P_{0} / \gamma^{\prime} H_{\mathrm{c}}\right) \quad\left(H_{\mathrm{c}} / D=1.0, D=1.0 \mathrm{~m}\right)$

As shown in Fig. 19, the value of $\eta$ decreases (from 1.0 to 0.26 ) approximately linearly with the increase of $P_{0} / \gamma^{\prime} H_{c}$ (from 0 to 0.87 ). As 


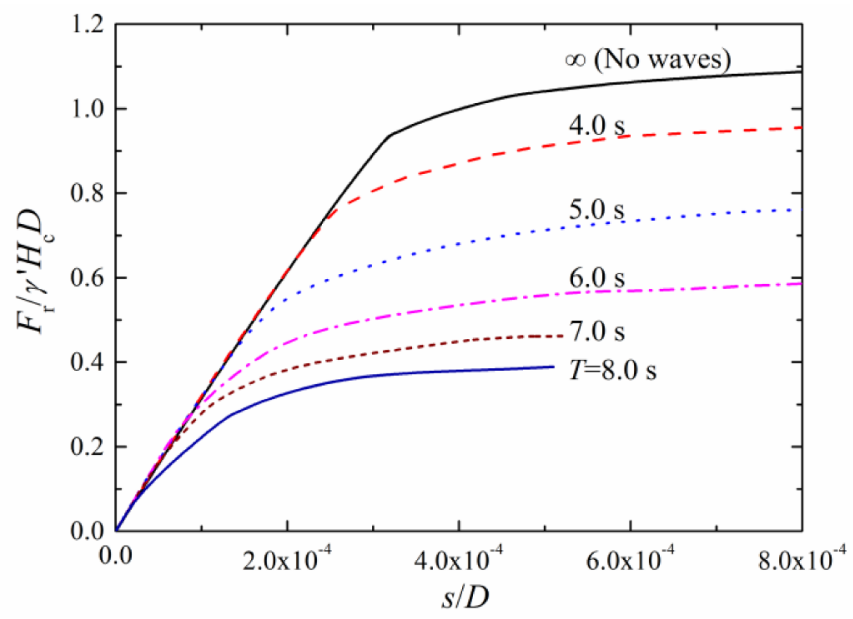

(a)

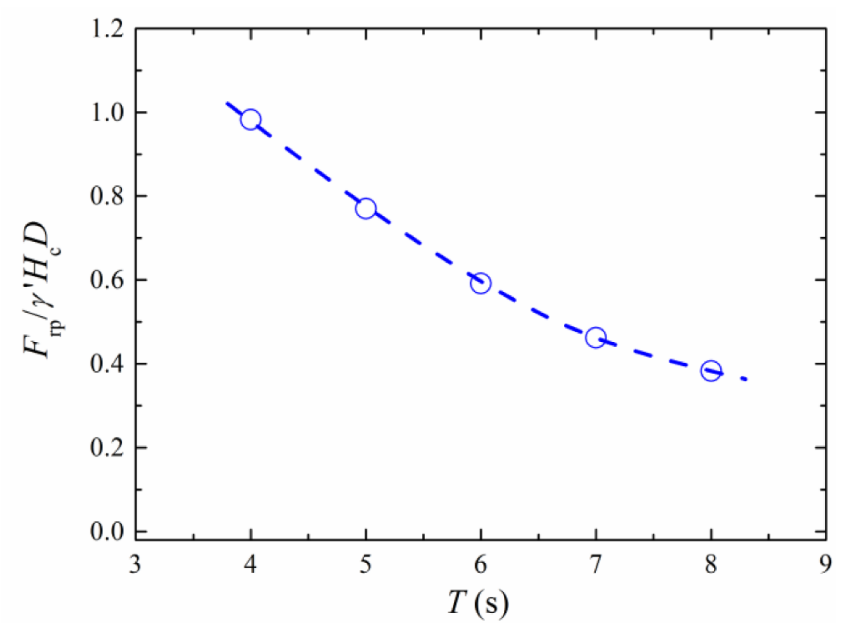

(b)

Fig. 14. Effects of wave period on (a) normalized force-displacement curves of uplifted pipelines; and (b) normalized peak vertical soil resistance of buried pipelines (the values of the parameters except $T$ are given in Table 1).

such, the influence of wave loading is unignorable for the prediction of vertical soil resistance to a burial pipeline.

\section{Conclusions}

Under wave troughs of progressive ocean waves, the vertical effective stress of soil can be reduced, especially in shallow waters. Consequently, the vertical soil resistance of the soil to a buried pipeline could be compromised significantly. In this study, a poro-elastoplastic model is proposed to investigate the effects of wave-induced porepressure on the uplift responses of a shallowly-buried pipe. The proposed numerical model is capable of sequentially simulating the porepressure generation in a sandy seabed under waves and the plastic-zone development while uplifting the pipe. Following conclusions can be drawn:

(1) Under wave troughs, additional uplift force can be induced due to non-uniform distribution of wave-induced pore-pressures along the pipe periphery. The value of uplift force is mainly dependent on the normalized amplitude of wave-induced pore-pressure at the mudline for the examined pipe burial-depth.

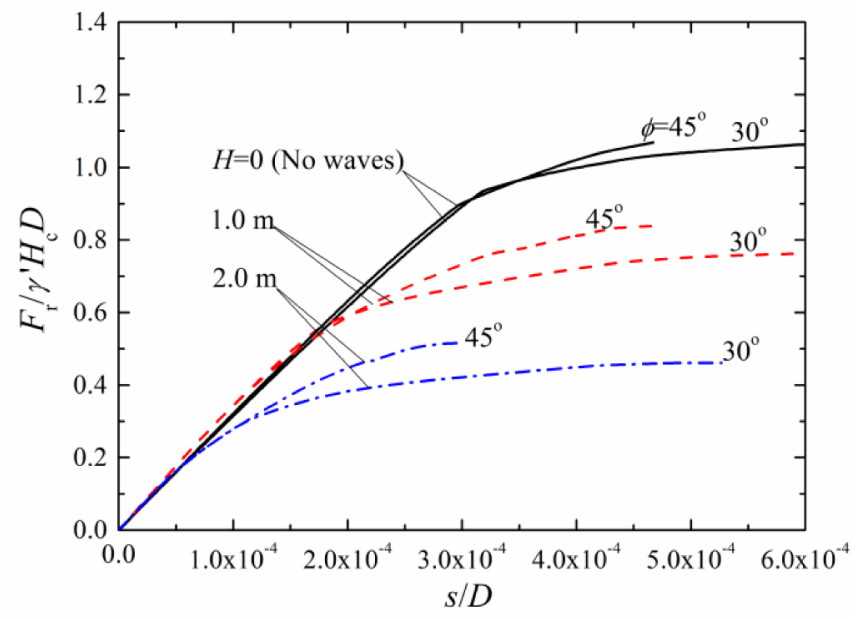

(a)

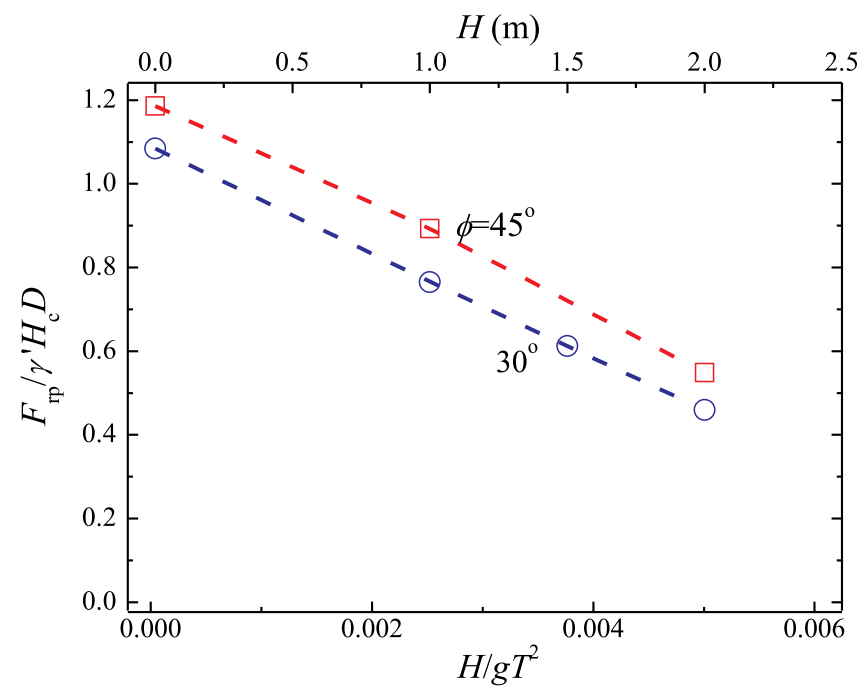

(b)

Fig. 15. Effects of peak friction angle: (a) normalized force-displacement curves of uplifted pipelines; and (b) variation of normalized $F_{\mathrm{rp}}$ with $H$ for two different values of $\phi$.

(2) Parametric study indicates that the wave-induced pore-pressure in the seabed has significant influence on the interactions between an uplifted pipe and surrounding soil. The peak vertical soil resistance decreases with increasing wave height and wave period, respectively.

(3) The initial stiffness of the normalized force-displacement curves is not affected by the peak friction angle, while the normalized peak vertical soil resistance is obviously increased by a larger peak friction angle. In contrast, the elastic modulus of soil mainly affects the initial stiffness of the normalized force-displacement curves while the peak vertical soil resistance generally keeps constant.

(4) A resistance-reduction coefficient is introduced to qualitatively characterize the effect of wave loading. The resistance-reduction coefficient generally decreases linearly with the increase of normalized amplitude of wave pressure at seabed mudline. The influence of wave loading is unignorable for the prediction of vertical soil resistance to a burial pipe. 


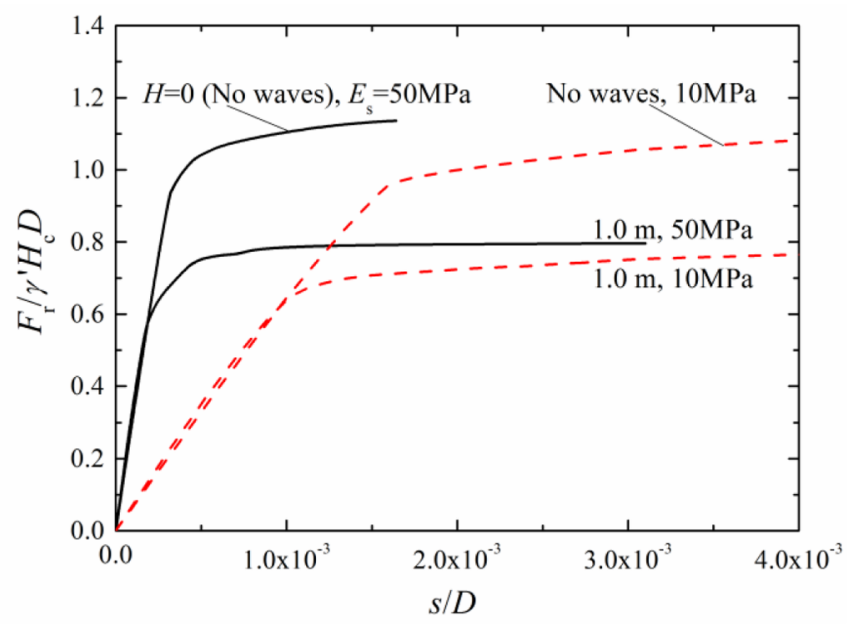

Fig. 16. Comparison of normalized force-displacement curves of uplifted pipelines between conditions with and without waves for two different values of $E_{\mathrm{s}}$.

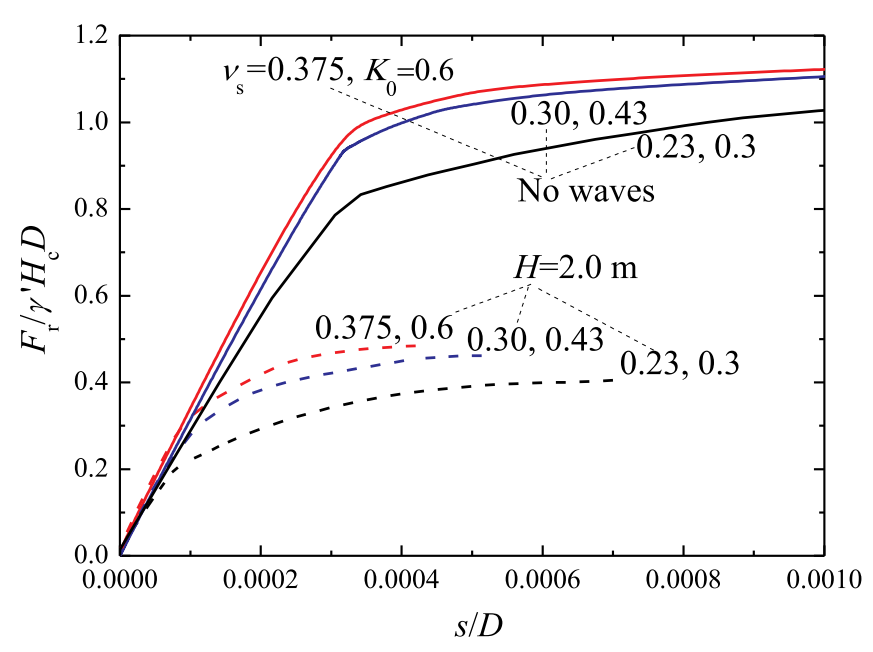

(a)

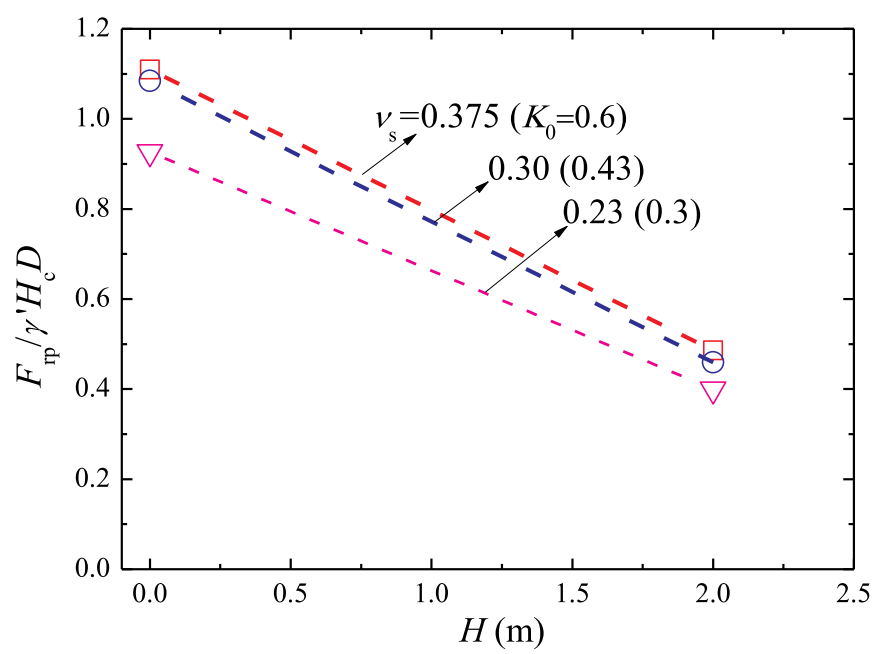

(b)

Fig. 17. Effects of Poisson ratio of soil: (a) normalized force-displacement curves of uplifted pipelines; and (b) variation of normalized $F_{\mathrm{rp}}$ with $H$ for three typical values of $\nu_{\mathrm{s}}$.

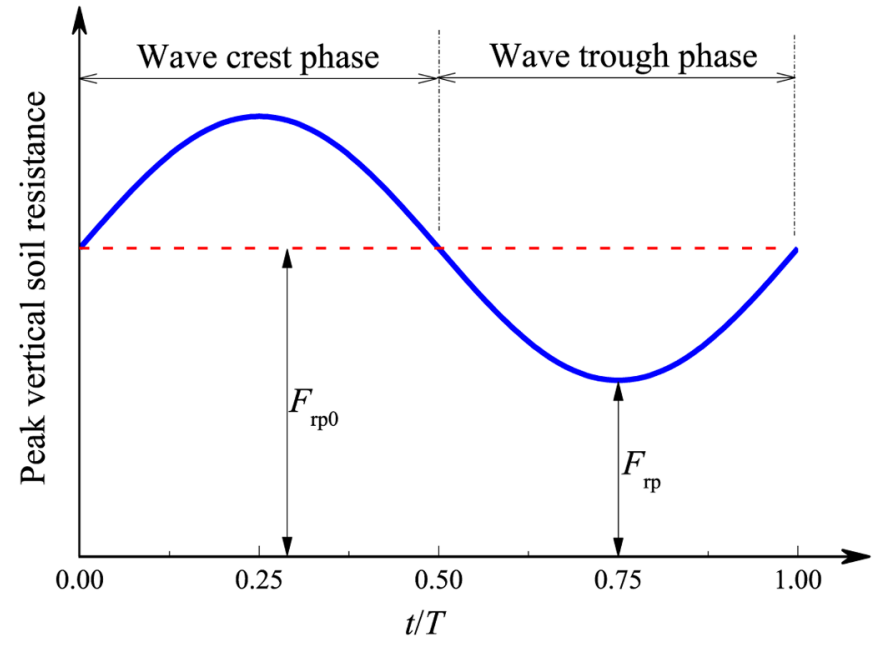

Fig. 18. Schematic diagram on the variation of the peak vertical soil resistance during a wave period.

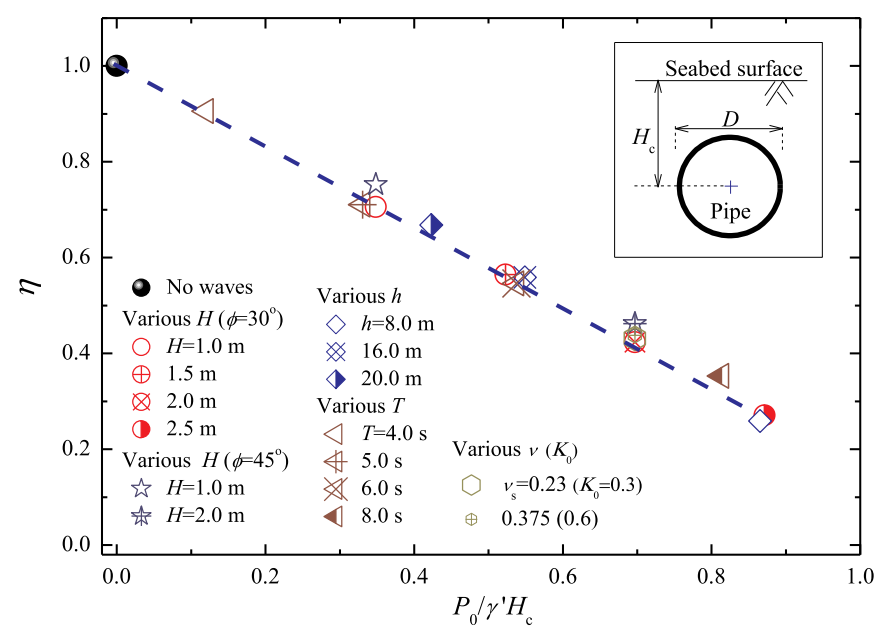

Fig. 19. Relationship between resistance-reduction coefficient and the normalized amplitude of wave pressure at the seabed mudline $\left(H_{\mathrm{c}} / D==1.0\right.$, $D==1.0 \mathrm{~m})$.

\section{Declaration of Competing Interest}

This is to confirm that all authors of this manuscript have directly participated in planning, execution and analyses of the study. The contents of this manuscript have been never published/copyrighted nor under consideration for publication elsewhere.

There are no directly related papers ever published or to be published by any author.

\section{Acknowledgments}

This work was financially supported by the National Natural Science Foundation of China (Grant Nos. 11825205, 11602273), the Strategic Priority Research Program (Type-B) of Chinese Academy of Sciences (Grant No. XDB22030000).

\section{Supplementary materials}

Supplementary material associated with this article can be found, in the online version, at doi:10.1016/j.apor.2019.102024. 


\section{References}

[1] B.W. Byrne, J. Schupp, C.M. Martin, A. Maconochie, J. Oliphant, D. Cathie, Uplift of shallowly buried pipe sections in saturated very loose sand, Géotechnique 63 (5) (2013) 382-390.

[2] R. Chen, L. Wu, B. Zhu, D. Kong, Numerical modelling of pipe-soil interaction for marine pipelines in sandy seabed subjected to wave loadings, Appl. Ocean Res. 88 (2019) 233-245.

[3] W.Y. Chen, G.X. Chen, W. Chen, C.C. Liao, H.M. Gao, Numerical simulation of the nonlinear wave-induced dynamic response of anisotropic poro-elastoplastic seabed, Marine Georesour. Geotechnol. (2018), https://doi.org/10.1080/1064119X.2018. 1507064.

[4] C.Y. Cheuk, D.J. White, M.D. Bolton, Uplift mechanisms of pipes buried in sand, J. Geotech. Geoenviron. Eng. 134 (2) (2008) 154-163.

[5] E.C. Clukey, C.R. Jackson, J.A. Vermersch, S.P. Koch, W.C. Lamb, Natural densification by wave action of sand surrounding a buried offshore pipeline, 21st Annual Offshore Technology Conference, Houston, Tex., 1989, pp. 291-300.

[6] R.F. Craig, Craig's Soil Mechanics, (7th ed.), Spon Press, London and New York, 2004.

[7] M.B. de Groot, M.D. Bolton, P. Foray, P. Meijers, A.C. Palmer, R. Sandven, Physics of liquefaction phenomena around marine structures, J. Waterw. Port Coast. Ocean Eng. 132 (4) (2006) 227-243.

[8] B.M. Das, Advanced Soil Mechanics, (3rd ed.), Taylor \& Francis, New York, 2008.

[9] Det Norske Veritas and Germanischer Lloyd. Global buckling of submarine pipelines. DNV-RP-F110, 2018.

[10] Det Norske Veritas and Germanischer Lloyd. Pipe-soil interaction for submarine pipelines. DNVGL-RP-F114, 2017.

[11] L. Duan, C. Liao, D. Jeng, L. Chen, 2D numerical study of wave and current-induced oscillatory non-cohesive soil liquefaction around a partially buried pipeline in a trench, Ocean Eng. 135 (2017) 39-51.

[12] F.P. Gao, Flow-pipe-soil coupling mechanisms and predictions for submarine pipeline instability, J. Hydrodyn. 29 (5) (2017) 763-773.

[13] F.P. Gao, D.S. Jeng, H. Sekiguchi, Numerical study on the interaction between nonlinear wave, buried pipeline and non-homogenous porous seabed, Comput. Geotech. 30 (6) (2003) 535-547.

[14] F.P. Gao, J.H. Li, W.G. Qi, C. Hu, On the instability of offshore foundations: theory and mechanism, Sci. China Phys. Mech. Astron. 58 (12) (2015) 124701.

[15] F.P. Gao, Y.X. Wu, Non-linear wave-induced transient response of soil around a trenched pipeline, Ocean Eng. 33 (3-4) (2006) 311-330.

[16] Hibbitt, D., Karlsson, B., Sorensen, P.Abaqus: analysis user's manual, Version 6.11. 2011.

[17] J.R.C. Hsu, D.S. Jeng, Wave-induced soil response in an unsaturated anisotropic seabed of finite thickness, Int. J. Numer. Anal. Methods Geomech. 18 (11) (1994) $785-807$.

[18] K. Ishihara, I. Towhata, Sand response to cyclic rotation of principal stress directions as induced by wave loads, Soils Found. 23 (4) (1983) 11-26.

[19] D.S. Jeng, Mechanics of wave-seabed-structure interactions: modelling, Processes and Applications, Shanghai Jiao Tong University Press, Shanghai, 2018.

[20] K. Li, Z. Guo, L.Z. Wang, H.Y. Jiang, Effect of seepage flow on Shields number around a fixed and sagging pipeline, Ocean Eng. 172 (2019) 487-500.

[21] W.G. MacDougal, S.H. Davidson, P.L. Monkmeyer, C.K. Sollitt, Wave-induced forces on buried pipelines, J. Waterw. Port Coast. Ocean Eng.-ASCE 14 (1988) 220-236.

[22] O.S. Madsen, Wave-induced pore pressures and effective stresses in a porous bed, Geotechnique 28 (4) (1978) 377-393.

[23] W. Magda, Wave-induced cyclic pore-pressure perturbation effects in hydrodynamic uplift force acting on submarine pipeline buried in seabed sediments, Coastal Eng. 39 (2000) 243-272.

[24] E.L. Matyas, J.B. Davis, Prediction of vertical earth loads on rigid pipes, . J. Geotech. Eng. ASCE 109 (2) (1983) 190-201.

[25] D.M. Potts, L. Zdravkovic, Finite Element Analysis In Geotechnical Engineering: Theory, Thomas Telford, London, 2001.

[26] W.G. Qi, F.P. Gao, Wave induced instantaneously-liquefied soil depth in a noncohesive seabed, Ocean Eng. 153 (2018) 412-423.

[27] W.G. Qi, C.F. Li, D.S. Jeng, F.P. Gao, Z.D. Liang, Combined wave-current induced excess pore-pressure in a sandy seabed, Coastal Eng. 147 (2019) 89-98.

[28] S. Sassa, H. Sekiguchi, Wave-induced liquefaction of beds of sand in a centrifuge, Geotechnique 49 (5) (1999) 621-638.

[29] S.E.J. Spierenburg, Wave-induced pore pressures around submarine pipelines, Coastal Eng. 10 (1986) 33-48.

[30] B. Stuyts, D. Cathie, T. Powell, Model uncertainty in uplift resistance calculations for sandy backfills, Can. Geotech. J. 53 (11) (2016) 1831-1840.

[31] B.M. Sumer, J. Fredsøe, S. Christensen, M.T. Lind, Sinking/floatation of pipelines and other objects in liquefied soil under waves, Coastal Eng. 38 (2) (1999) 53-90.

[32] C.H. Trautmann, T.D. O'Rourfce, F.H. Kulhawy, Uplift force-displacement response of buried pipe, J. Geotech. Eng. 111 (9) (1985) 1061-1076.

[33] M.B.C. Ulker, M.S. Rahman, D.S. Jeng, Wave-induced response of seabed: various formulations and their applicability, Appl. Ocean Res. 31 (1) (2009) 12-24.

[34] F. Wen, D.S. Jeng, J.H. Wang, X.L. Zhou, Numerical modeling of response of a saturated porous seabed around an offshore pipeline considering non-linear wave and current interaction, Appl. Ocean Res. 35 (2012) 25-37.

[35] D.J. White, C.Y. Cheuk, M.D. Bolton, The uplift resistance of pipes and plate anchors buried in sand, Geotechnique 58 (10) (2008) 771-779.

[36] D.J. White, E.C. Clukey, M.F. Randolph, et al., The state of knowledge of pipe-soil interaction for on-bottom pipeline design, Offshore Technology Conference, Paper OTC-27623-MS, 2017.

[37] E.S. Williams, B.W. Byrne, A. Blakeborough, Pipe uplift in saturated sand: rate and density effects, Géotechnique 63 (11) (2013) 946-956.

[38] T. Yamamoto, H.L. Koning, H. Sellmeijer, E.V. Hijum, On the response of a poroelastic bed to water waves, J. Fluid Mech. 87 (1) (1978) 193-206.

[39] S. Yimsiri, K. Soga, K. Yoshizaki, G.R. Dasari, T.D. O’Rourke, Lateral and upward soil-pipeline interactions in sand for deep burial-depth conditions, J. Geotech. Geoenviron. Eng. 130 (8) (2004) 830-842.

[40] H.Y. Zhao, D.S. Jeng, C.C. Liao, J.F. Zhu, Three-dimensional modeling of waveinduced residual seabed response around a mono-pile foundation, Coastal Eng. 128 (2017) 1-21.

[41] X.L. Zhou, J.H. Wang, J. Zhang, D.S. Jeng, Wave and current induced seabed response around a submarine pipeline in an anisotropic seabed, Ocean Eng. 75 (2014) $112-127$. 